\title{
An Investigation of the Relationship Between Tritium in Groundwater and the Dendrochronology of Tritium in Trees at the Savannah River Site (U)
}

by

C. E. Murphy Jr.

Westinghouse Savannah River Company

Savannah River Site

Aiken, South Carolina 29808

R. M. Kalin

Dept. of Civil Engn. - The Queen's University of Belfast

Nor. Ireland

DOE Contract No. DE-AC09-89SR18035

This paper was prepared in connection with work done under the above contract number with the U. S.

Department of Energy. By acceptance of this paper, the publisher and/or recipient acknowledges the U. S. Government's right to retain a nonexclusive, royalty-free license in and to any copyright covering this paper, along with the right to reproduce and to authorize others to reproduce all or part of the copyrighted paper. 


\section{DISCLAIMER}

This report was prepared as an account of work sponsored by an agency of the United States Government. Neither the United States Government nor any agency thereof, nor any of their employees, makes any warranty, express or implied, or assumes any legal liability or responsibility for the accuracy, completeness, or usefulness of any information, apparatus, product, or process disclosed, or represents that its use would not infringe privately owned rights. Reference herein to any specific commercial product, process, or service by trade name, trademark, manufacturer, or otherwise does not necessarily constitute or imply its endorsement, recommendation, or favoring by the United States Government or any agency thereof. The views and opinions of authors expressed herein do not-necessarily state or reflect those of the United States Government or any agency thereof.

This report has been reproduced directly from the best available copy.

Available to DOE and DOE contractors from the Office of Scientific and Technical Information, P.O. Box 62, Oak Ridge, TN 37831; prices available from (615) 576-8401.

Available to the public from the National Technical Information Service, U.S. Department of Commerce, 5285 Port Royal Road, Springfield, VA 22161. 


\title{
An Investigation of the Relationship between Tritium in Groundwater and the Dendrochronology of Tritium in Trees at the SRS
}

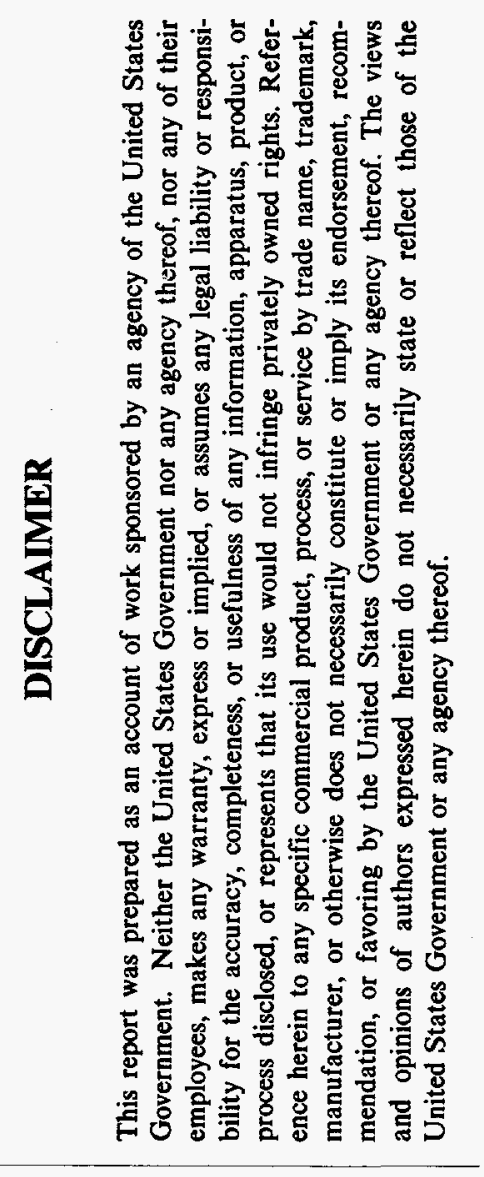

\author{
Final Report: \\ Submitted to ERDA and \\ The Westinghouse Savannah River Company \\ February 1995 \\ by
}

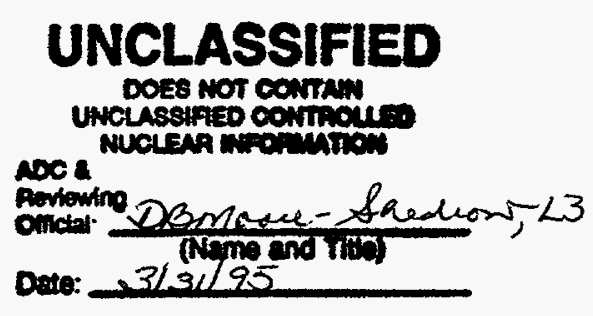

Robert M. Kalin, PI

Department of Civil Engineering

The Queen's University of Belfast

Belfast BT7 1NN Northern Ireland

Research Conducted at:

Center for Applied Isotope Studies

University of Georgia, Athens, GA 30602

MASTER 


\section{DISCLAIMER}

Portions of this document may be illegible in electronic image products. Images are produced from the best available original document. 
Table of Contents

Project Summary 1

Introduction $\quad 2$

Objectives of study $\quad 5$

Methodology 6

$\begin{array}{ll}\text { Par bomb proceedures } & 11\end{array}$

$\begin{array}{ll}\text { Liquid scintillation methods } & 14\end{array}$

$\begin{array}{ll}\text { Vaccum line and chemistry memory effects } & 14\end{array}$

$\begin{array}{ll}\text { Results of tritium in tree-rings } & 16\end{array}$

X-Ray flourescence methods and results $\quad 22$

$\begin{array}{ll}\text { Gamma-ray spectrometry methods and results } & 24\end{array}$

$\begin{array}{ll}\text { Conclusions } & 26\end{array}$

$\begin{array}{ll}\text { References } & 27\end{array}$

Figures

Figure 1. Site location 3

Figure 2. Cellulose structure 4

Figure 3. Schematic of vacuum line 12

$\begin{array}{ll}\text { Figure 4. Memory effects } & 15\end{array}$

$\begin{array}{ll}\text { Figure 5. Lignin and Cellulose tritium } & 17\end{array}$

$\begin{array}{ll}\text { Figure 6. Early tree-ring tritium values } & 18\end{array}$

Figure 7. Relationship of tree-ring tritium with F\&H seepage basins 19

Figure 8. Relationship of tree-ring tritium with Four Mile Creek water 21

Figure 9. X-ray flourescence results 23

Figure 10. Gamma counting results 25

Plates

Plate 1. Photo of surfacing method 7

Plate 2. Photo of ring separation technique 8

Plate 3. Photo of dendrochronological marking 9 
Tables

Table 1a. Results of counting lignin fraction

Table $1 \mathrm{~b}$. Results of counting hollocellulose fraction

32

Table 2a. Results of X-ray flourescence

Table $2 \mathrm{~b}$. Results in ppm selected metals in tree-rings

37

Table 3. Gamm counting results 
This project was supported through ERDA to demonstrate that the temporal distribution of tritium can be documented by the analysis of bound hydrogen in annual tree-ring samples. The project focuses on two sample locations at the Savannah River Site (SRS), a nuclear material production facility located in Aiken, SC. The SRS provided samples of cross-sections from a single tree that were to be pooled together for analysis. Annual tree-rings were identified in each cross-section sample and separated for the period 1954 to 1993 . These annual samples were ground and chemically treated to separate the hollocellulose fraction of the wood, then subsequently combusted and the resulting water counting using low-level liquid scintillation counting equipment. Additionally, the ground annual tree-rings were gamma-counted to determine any temporal variation in radionuclide activity and analyzed with $\mathrm{X}$-ray fluorescence to find any temporal variation in traceelement concentrations. This report presents the results and is intended to be a compilation of the work. 


\section{Introduction}

The Savannah River Site (SRS) is located in the state of South Carolina, USA (Figure 1), and is a nuclear materials production and reprocessing facility that was established in 1950 by the US Government for purposes of national defense. One consequence of SRS operations has been repeated atmospheric and liquid releases, both planned and accidental, of radionuclides, organic and heavy metal contaminants to the environment. Recent publications issued by the Westinghouse Savannah River Company (WSRC), which manages operation at the site, report the releases of approximately 24 million curies (Ci) of tritium since the initiation of SRS operation. Most of the tritium released to the atmosphere, surface water, and groundwater was as a result of routine procedures such as reactor operations, transuranic element recover, laboratory research and reprocessing of heavy water (Murphy et al., 1991). In addition, some $3000 \mathrm{Ci}$ of ${ }^{14} \mathrm{C}$ have been released to the atmosphere as a result of production reaction operations (Carlton et al. 1993).

The use of annual tree-rings for the study of environmental levels of tritium began as early as 1961 (Kigoshi and Tomikura, 1961). A number of studies in more recent years have demonstrated that analyses of tritium in tree rings can provide historic reference values for determining natural and anthropogenically derive variations in local radionuclide concentrations (Kozak, Obelic and Jorvanticic, 1989, Momoshima, Takashima, Hakozaki and Okai, 1990). Tritium is incorporated through the photosynthetic process into the structure of plant tissue during the growing season (Figure 2), and thus, the wood cellulose preserves the isotopic signature of the air moisture, $\mathrm{CO}_{2}$, soil water and groundwater of the immediate environment surrounding the tree. Tree-rings can provide a temporal and spatial record of tritium concentration above natural levels.

Present invasive monitoring of groundwater contamination is costly. The installation of monitoring wells is presently required to determine levels of suspected groundwater tritium. The determination of occurrence and movement of tritium release in the groundwater is essential to determine the present and future exposure of SRS employees and the public. 


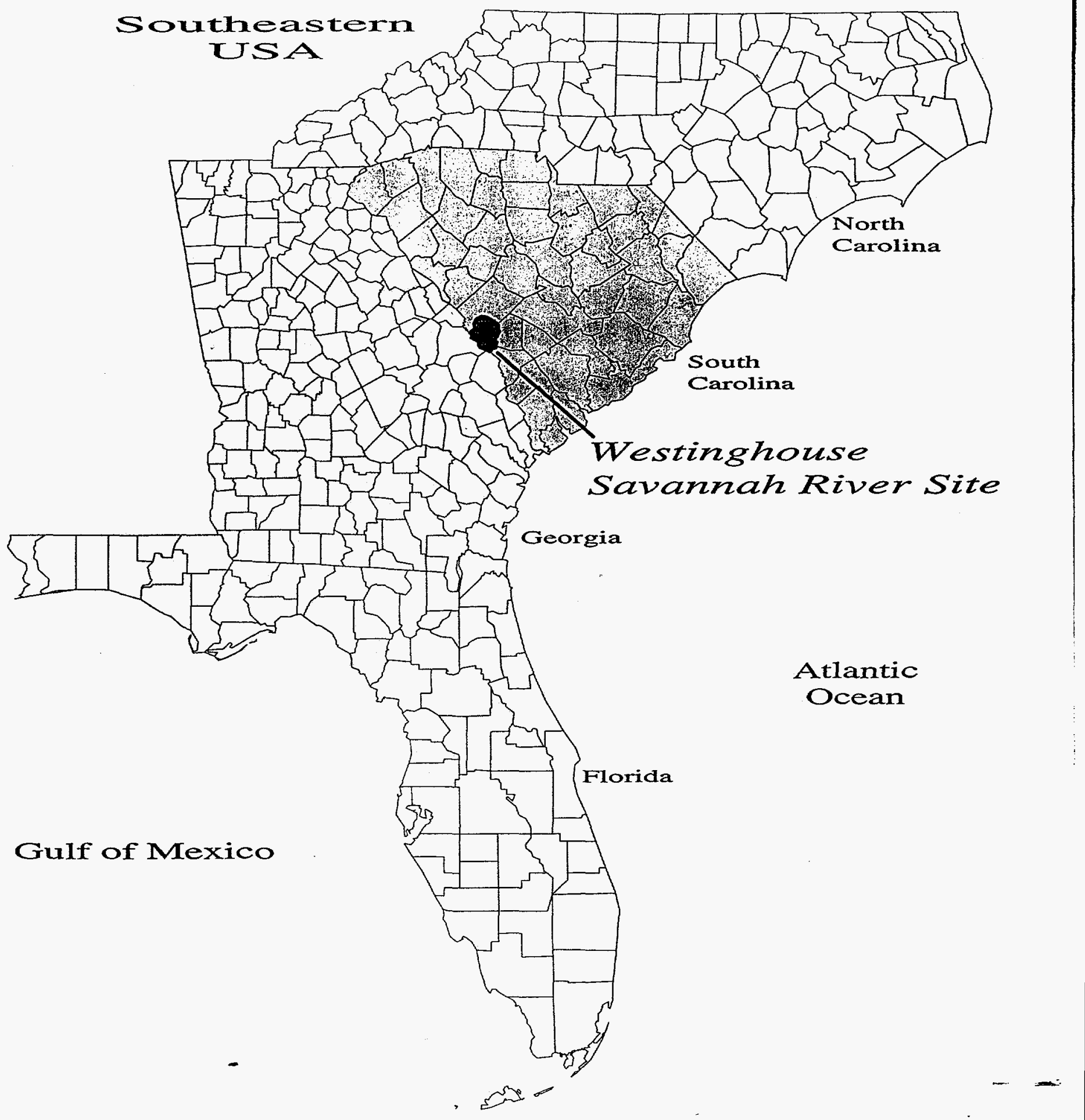

Figure 1. Location of Westinghouse Savannah River Site 


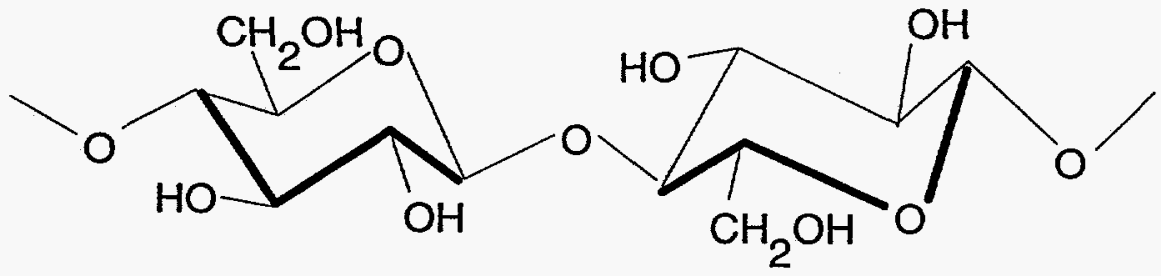

Portion of Cellulose Chain; Ring hydrocarbons have been omitted for clarity.

Figure 2. Structure of the cellulose molecule showing the bound $\mathrm{C}-\mathrm{H}$ bonds. 


\section{Objectives of the Study}

The primary objectives of the research programs are as follows:

- To begin a pilot study to measure tritium values in annual rings from trees collected at the SRS in order to date the history and relative concentration of tritium;

- To demonstrate that the history of tritium in areas affected by SRS tritium releases can be effectively differentiated in order to prove a methodology for a rapid, cost effective means of future monitoring of groundwater contaminant plumes resulting from accidental radionuclide releases; and

- To relate the concentration of tritium as measured in tree rings to the levels of tritium at onsite monitoring locations during the time period of interest.

Subsequent to the primary objective, two additional research objectives were investigated:

- To investigate variation in the annual tree ring concentration of radionuclides by gammaspectrometry;

- To investigate variations in trace element concentration in annual tree rings using X-Ray Fluorescence methodology. 


\section{Methodology}

Samples were collected from trees at onsite SRS locations near existing SRS water monitoring stations where historic data clearly reflected some of the major radionuclide releases during the 40 years covering 1950-1990. One tree was sacrificed to produce a large samples for testing. The cross-sections will represent one sample site.

Cross-sections of a single tree supplied by SRS were sawed to a thickness of ca. $5 \mathrm{~cm}$ to facilitate surfacing and tree-ring separation. Each cross-section (labelled 1 - 4) was then sawed in half resulting in 8 half sections. Each half section was sanded with a belt sander with sequential grit of 50,100, 200 and a hand-finishing sand with 400 grit (Plate 1). This sanding brought out the ring structure and allowed for the identification of annual growth rings. Some false rings existed within annual growth bands, but could be identified by examination around the circumference. The bark was removed from each half section (Plate 2), and marks were placed with a dissecting needle on the 3 half sections to be separated. Each decade was marked with two dots, and each pentad with one dot around the circumference of the half section (Plate 3). Using an exacto-knife, a cut was then made between the early-wood late-wood boundary of each consecutive ring. The individual rings were then carefully chiseled off using the same technique shown in Plate 2, and placed in a labelled sample bag. Following the removal of each ring, the outside surface of the half-sections were sanded with the belt sander to avoid subsequent rings from being contaminated with residual wood from the one previously removed.

The chiseled bits of each tree-ring from the cross-section were then ground into fine sawdust ( 1 to $2 \mathrm{~mm}$ size fraction) and placed back into the originally labelled sample bag. After labelling the beaker and noting sample year in the lab book, 250 grams of each sample was placed in a 1 liter beaker and $750 \mathrm{ml}$ of toluene was added to the sample. The beaker was placed in an ultra-sonic bath for an hour, to remove resins. The toluene was decanted and a second toluene wash was applied if needed. After decanting all the toluene, $750 \mathrm{ml}$ of ethanol was added to each sample, and the beaker was placed in an ultrasonic bath. This acts to remove residual toluene and resins. 


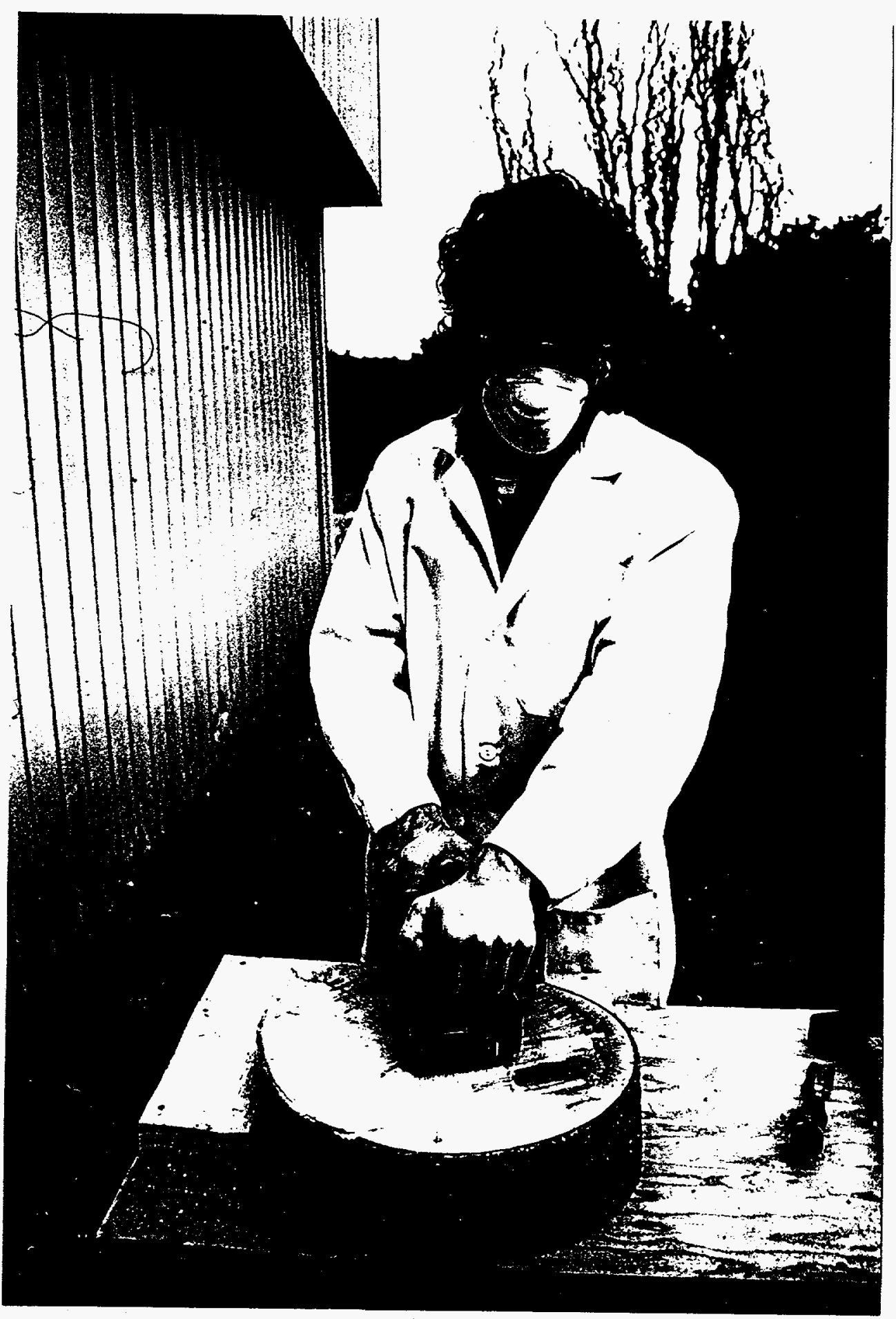

Plate 1. Photograph showing method of surfacing the tree cross-section for dendrochronological determination. 
UOIJOAS-SSOIO

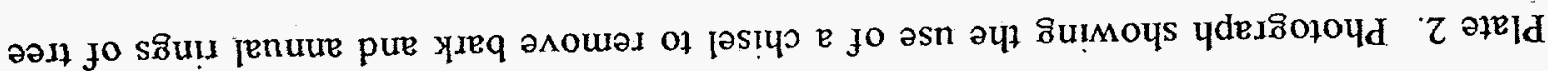

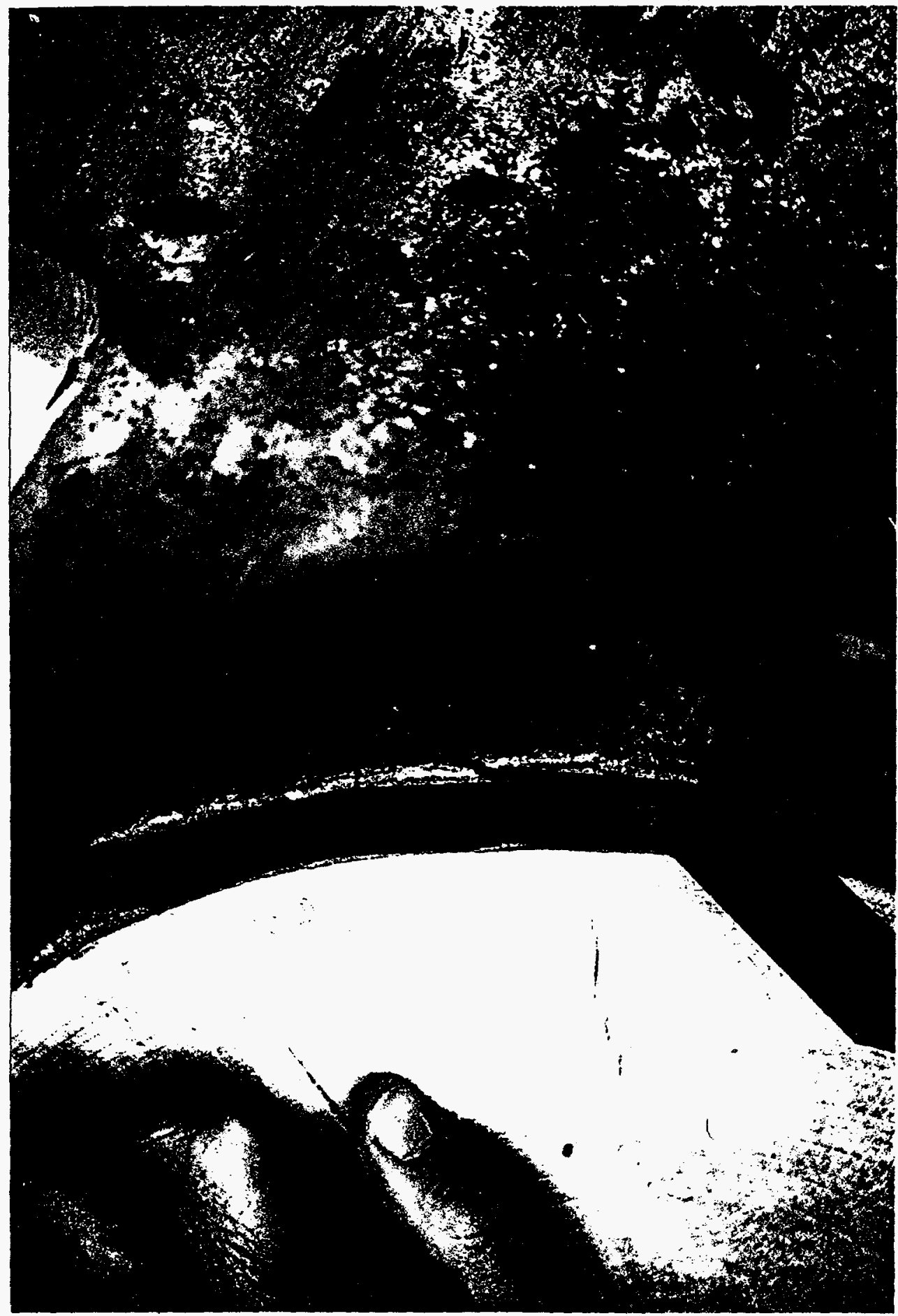




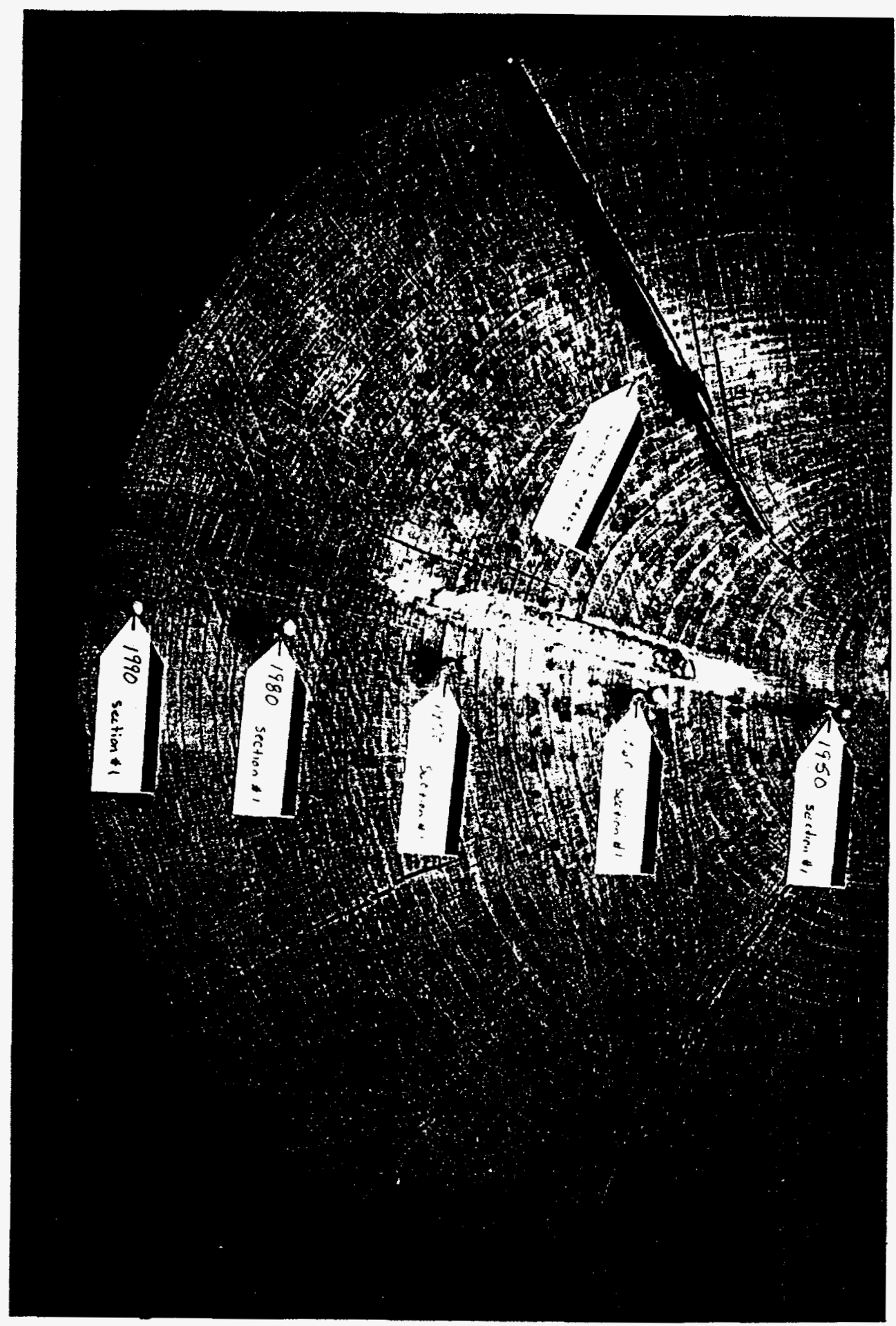

Plate 3. Photograph of dendrochronologically dated tree cross-section. Decades and pentads are marked along a number of radii of the cross section for easy identification. 
The samples were then dried in a drying oven for three days minimum or until no residual ethanol was detected. The samples were boiled and rinsed several times (three minimum) in $750 \mathrm{ml}$ of distilled water and dried in a drying oven at $110^{\circ} \mathrm{C}$. This was to remove sugars and water soluble material from the wood and to ensure the removal of any residual toluene or ethanol.

Each sample was then chemically treated to the separate hollocellulose and to exchange mobile hydrogen. 100 grams of the boiled sample was added to $750 \mathrm{ml}$ of distilled water and heated to just below boiling. To the sample $\sim 10$ drops of phosphoric acid and ca. $0.5 \mathrm{~g}$ of sodium chlorite was added. Sodium chlorite was added every hour for 8 - 10 hours, and the mixture was stirred vigorously each time; another $\sim 10$ drops of phosphoric acid was added approximately halfway through the process. This solution became a deep yellow color which intensified with time. The sample was rinsed repeatedly in hot distilled water until the solution was clear. One set of annual rings were treated with only one day of this process, yielding light tan colored cellulose/lignin. These samples were dried at $110^{\circ} \mathrm{C}$ and stored in plastic bags. A second subset of the annual rings was treated until there was pure white hollocellulose. This required the treatment to continue from two to four days. This pure white hollocellulose was rinsed repeatedly in hot distilled water until the solution was clear. These samples were dried at $110^{\circ} \mathrm{C}$ and stored in plastic bags.

Pellets of the bleached sawdust were made using a Spex 1.25 inch pellet die at $23,000 \mathrm{lbs}$ (10 tons/sp in.). These pellets were desiccated in a vacuum-oven for a minimum of 24 hours prior to combustion. $\sim 15 \mathrm{~g}$ of pelletized wood was then combusted, and the water was cryogenically separated from oxygen and carbon dioxide, collected and stored and the appropriate information recorded in lab book and on $5 \times 7$ inch index card. The stored samples were labelled with the year of each ring and labelled XS1 for 1st chemical treatment and XS2 for second chemical treatment. Additionally, pure analytical cellulose (from uncontaminated source) was analyzed concurrent with the samples from SRS to check system blank. 
Figure 3 shows a schematic of the vacuum system used to combust the samples and collect the residual water. The following procedures were employed.

-Place sample in bomb crucible in such a manner that the sample is in good contact with the fuse wire.

-Carefully close and seal the bomb.

-Flush-out the interior of the bomb with $\mathrm{O}_{2}$, so as to force out atmospheric gases.

-Close the outlet valve, and connect to closed vacuum line.

-Fill the bomb with $\sim 450$ psi of $\mathrm{O}_{2}$.

-Close gauge valve and inlet valve, and remove $\mathrm{O}_{2}$ hose.

-Connect electrodes to bomb, and combust sample.

-Open gauge valve.

-Place a dry-ice ethanol slush around the first two traps to collect water

-Open the vacuum line, and slowly bleed $\mathrm{O}_{2}, \mathrm{CO}_{2}$ and the water sample through the vacuum line by opening the bomb outlet valve in small increments (one nudge every $10 \mathrm{~min}$ ), until the bomb gauge reads zero. Insure that the pressure in the vacuum line is not greater than $0.1 \mathrm{~atm}$. 


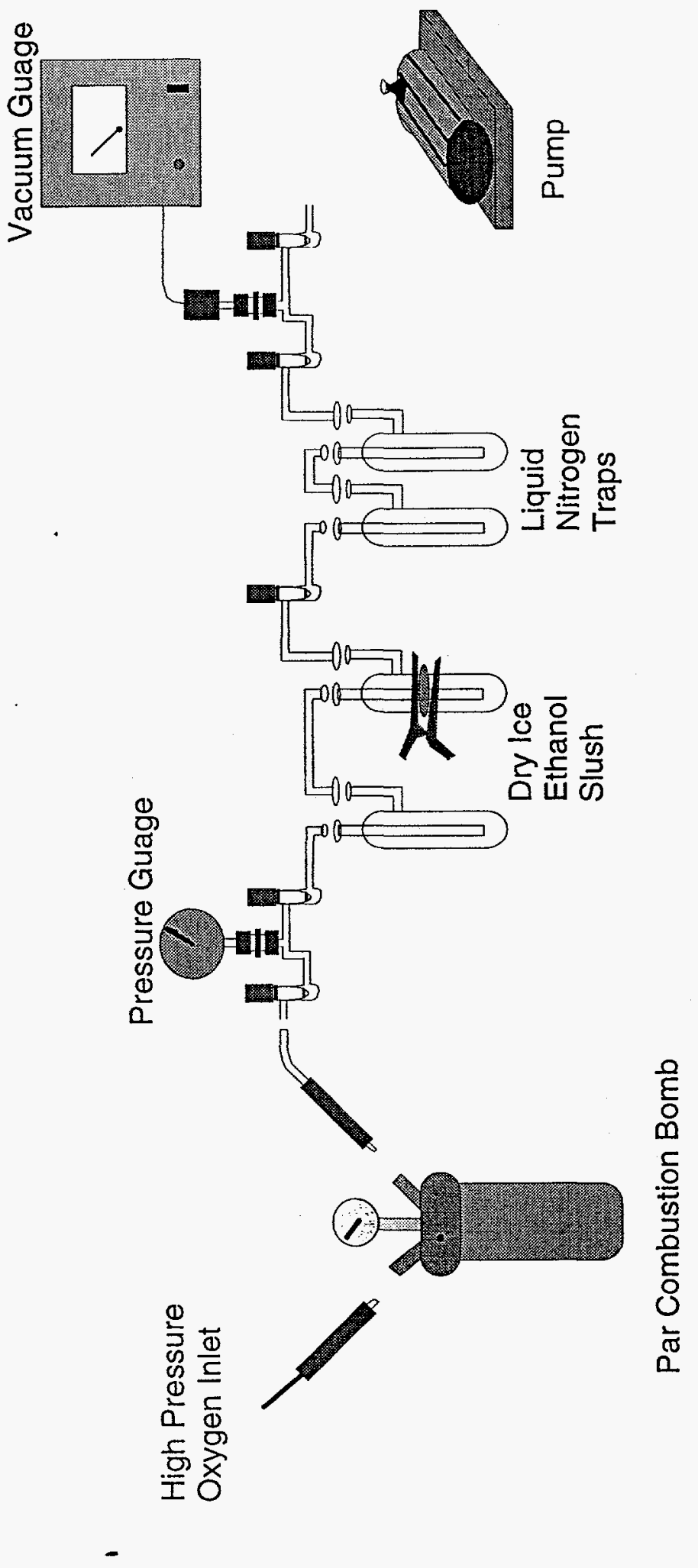

Figure 3. Schematic Diagram of the vacuum line system used for the combustion of cellulose samples and the cryogenic collection of water for tritium analysis. 
-After the bomb is evacuated, disconnect from vacuum line, and open valves to atmosphere so that the bomb can be opened.

-Pipet water which condensed in the bomb into a trap that is then attached to the vacuum line for distillation and purification.

-Open distillation system to vacuum line, and apply heat source.

-Once this is completed, close distillation apparatus from vacuum line. All water will be trapped within the two main cold-traps. Remove the dry ice/ethanol from each trap, and apply liquid $\mathrm{N}$ to the removable trap. To the other trap, apply a heat source so that all water will be evaporated and condensed in the LN trap.

-The frozen water is then be melted, and pipette into an appropriate vial for storage, and the weight noted on card. 


\section{Liquid Scintillation Methods}

The determination of tritium in the water collected from combustion of cellulose is accomplished as follows: in a $7 \mathrm{ml}$ plastic LSC vial, $1 \mathrm{ml}$ of water is weighed to the nearest $0.01 \mathrm{gm}$ and mixed with $5.0 \mathrm{ml}$ of Optiphase HiSafe 3 (Wallac Oy, Finland). This cocktail was used to ensure a single phase counting environment for the samples. Unexpectedly, the water samples collected after par-bomb combustion were $<\mathrm{pH} 2$. The normal high-load cocktail used for tritium determinations did not permit the use of low $\mathrm{pH}$ water. After experimentation, it was determined that Optiphase HiSafe 3 provided the most stable counting emulsion for the samples. The sample in the $7 \mathrm{ml}$ vial is placed in a $20 \mathrm{ml}$ teflon/plastic vial holder and counted in a Wallac Quantulus 1220 Low-Level Liquid Scintillation Counter. The counter set-up, spectrum and results of counting are stored on disk and hard copy for QA/QC purposes. The ratio of the countrate in the entire tritium energy region to the countrate of $50 \%$ of the tritium energy region was monitored to test for changes in counting conditions between samples. A copy of the counter set-up and output are in Appendix 1. Each sample is counted a minimum of 3 × 100 minutes.

\section{Vacuum Line and Chemical Memory Effects}

Three QA/QC blank hollocellulose samples were produced from analytical grade cellulose for XRF used, and were measured for tritium activity after par-bomb combustion. A single year (1975) hollocellulose sample was combusted just prior to these samples. The blank samples were combusted and collected using the identical glasswares and pipets in sequential order. The results of this exercise were intended to show the worst-case cross contamination of samples. Figure 4 shows the results of these samples along with that of the 1975 ring. The countrate of the blank samples did not equal the background (tritium free water) countrate. The analytical grade cellulose is most likely produced from modern plant matter that will contain a measurable amount of natural and anthropogenic tritium. The memory of the system is less that $1 \%$ between samples (Figure 4) and will have insignificant affects apon the interpretation of results. 


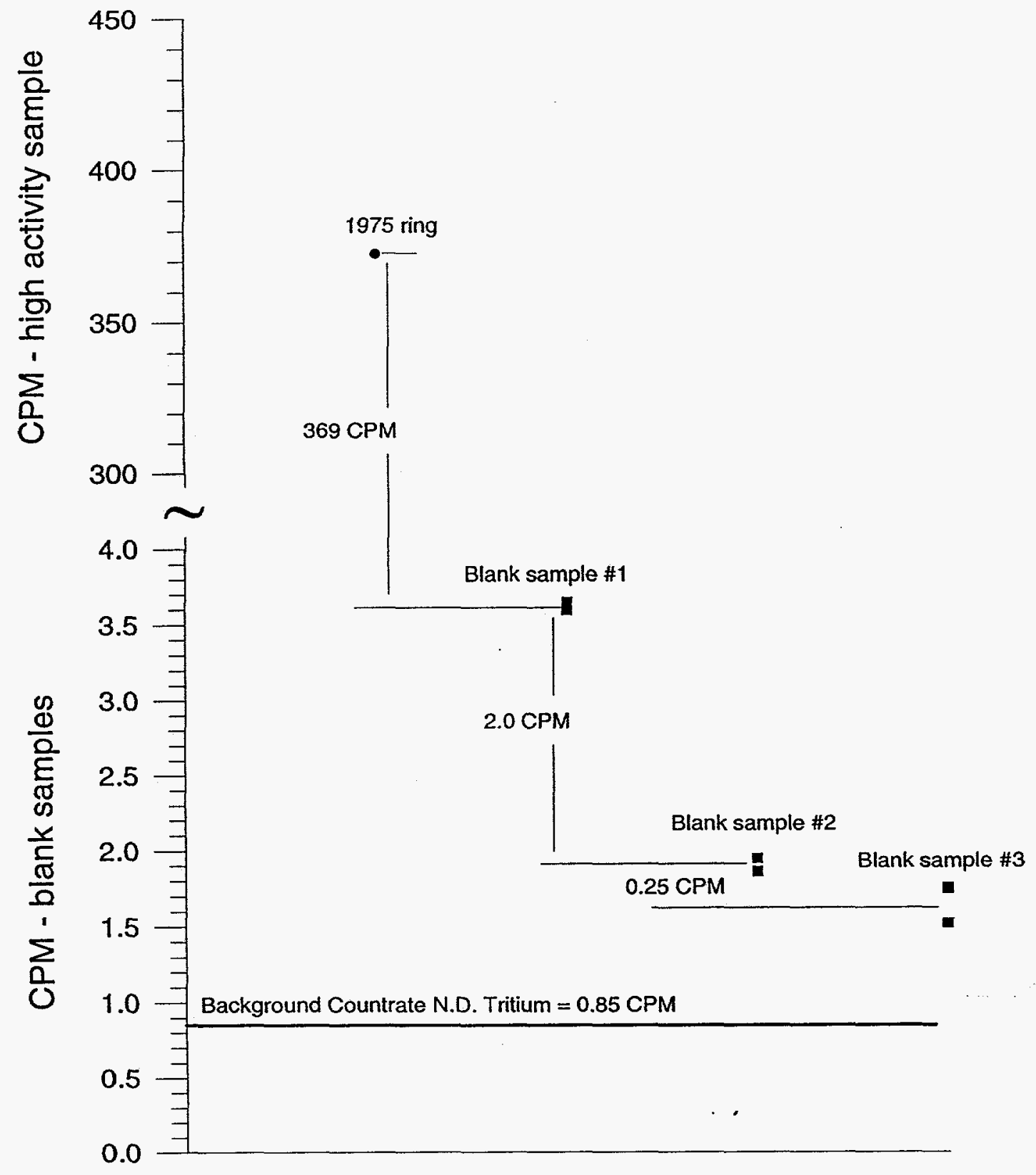

Figure 4. Results of liquid scintillation counting samples of analytical grade cellulose for determination of the memory effect of the chemistry, vacuum line and measurement systems. 


\section{Results of Tritium in Tree-Rings}

Samples between 1965 and 1990, treated with sodium chlorite for 1 day, were measured after par-bomb combustion (Table 1a), and hollocellulose samples between 1954 and 1993 were measured after par-bomb combustion (Table 1b). The results, corrected for radioactive decay, for these samples are nearly identical and show the same general trends (Figure 5). The impure cellulose samples measured for the period during the late 1960's show elevated tritium concentrations compared to the pure hollocellulose fraction. These results show a two order of magnitude change in the concentration of tritium in tree-rings during the period $1954-1993$.

The correction for radioactive decay most affects the samples from the earliest portion of the record. Figure 6 shows both uncorrected countrates and corrected tritium concentrations for the tree-rings between 1954 and 1972. The declining trend between 1954 and 1964 may suggest a decline in atmospheric tritium affecting the tree. It is also possible that for the oldest wood in the tree, additional chemical separation that exchanges nitrate at all of the exchangeable hydrogen sites would allow for more detailed analysis of small variations during this time period.

Comparison of the published flux of tritium reaching the Four Mile creek from the $\mathrm{F}$ and $\mathrm{H}$ seepage area basin with the reconstructed tritium in both Lignin-cellulose and Hollocellulose shows now correlation (Figure 7). Any variation in the concentration of tritium as reconstructed as part of this study are not related to the observed contamination from the $\mathrm{F}$ and $\mathrm{H}$ basins. 


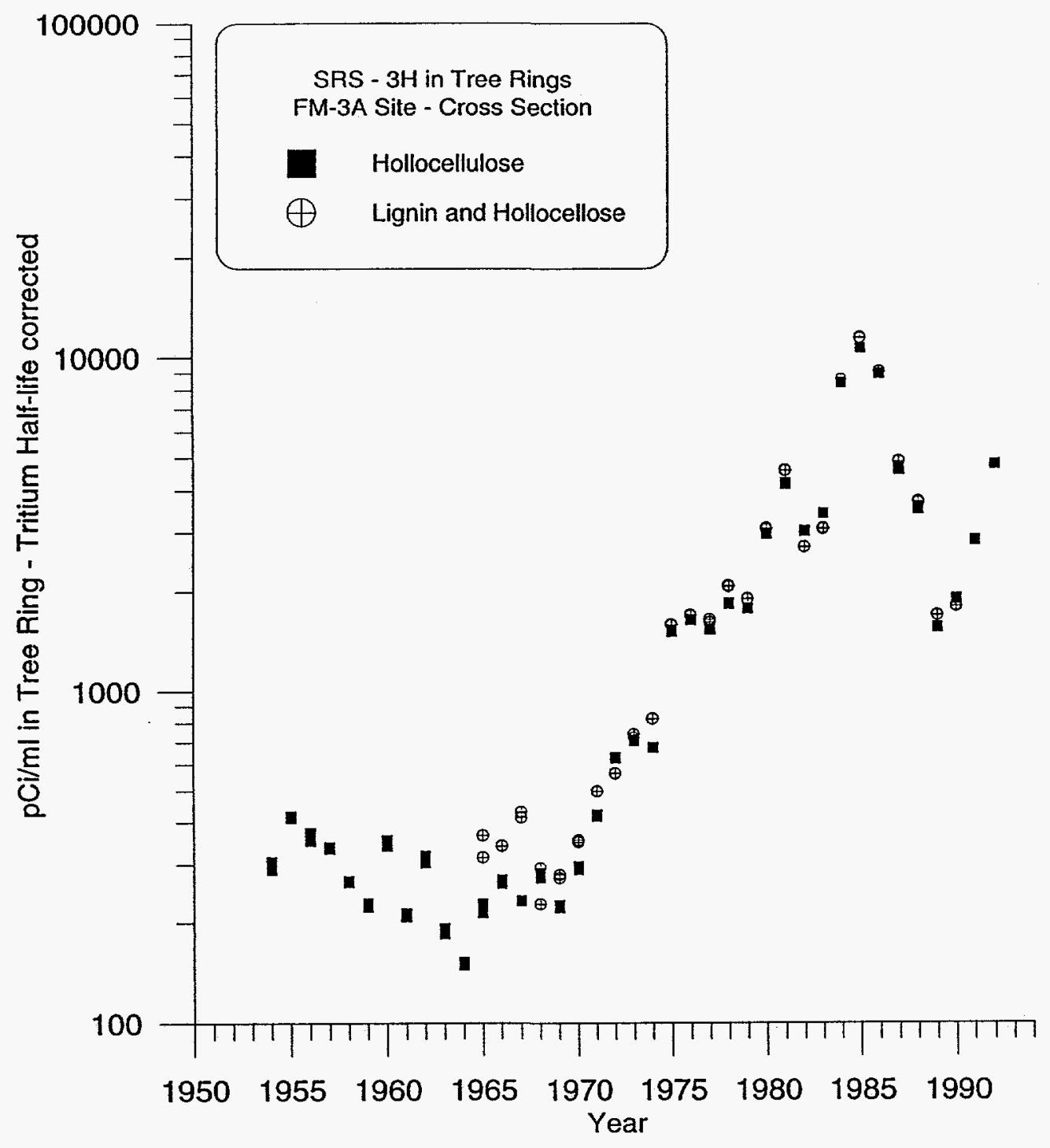

Figure 5. Results of-tritium in tree-rings corrected for radioactive decay. Both lignincellulose and hollocellulose fractions were chemically treated, combusted and measured for tritium concentration. The results are nearly identical for both fractions. 


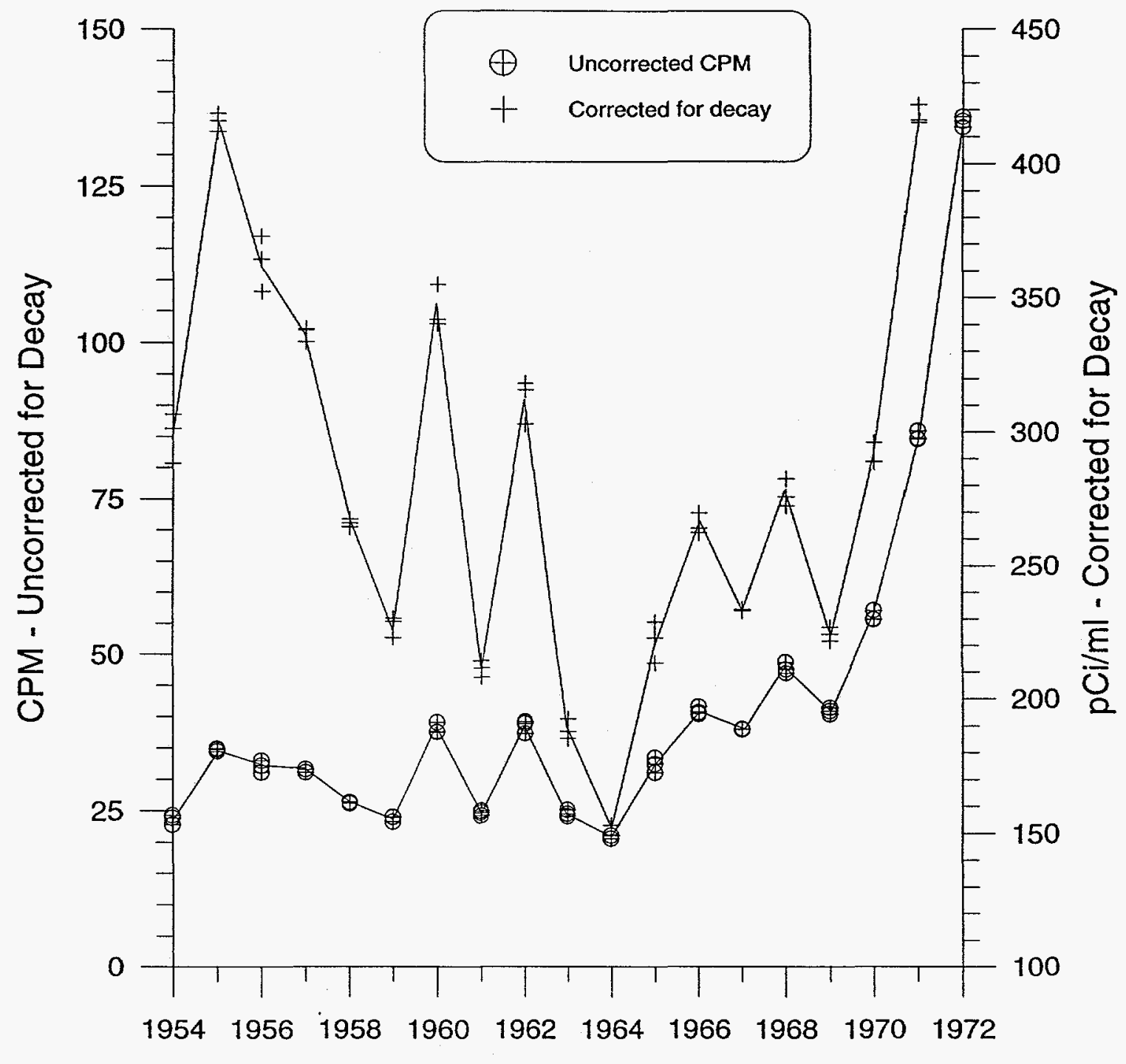

Figure 6. Tritium in hollocellulose for tree-rings between 1954 and 1972, uncorrected countrates and tritium concentration corrected for radioactive decay. 


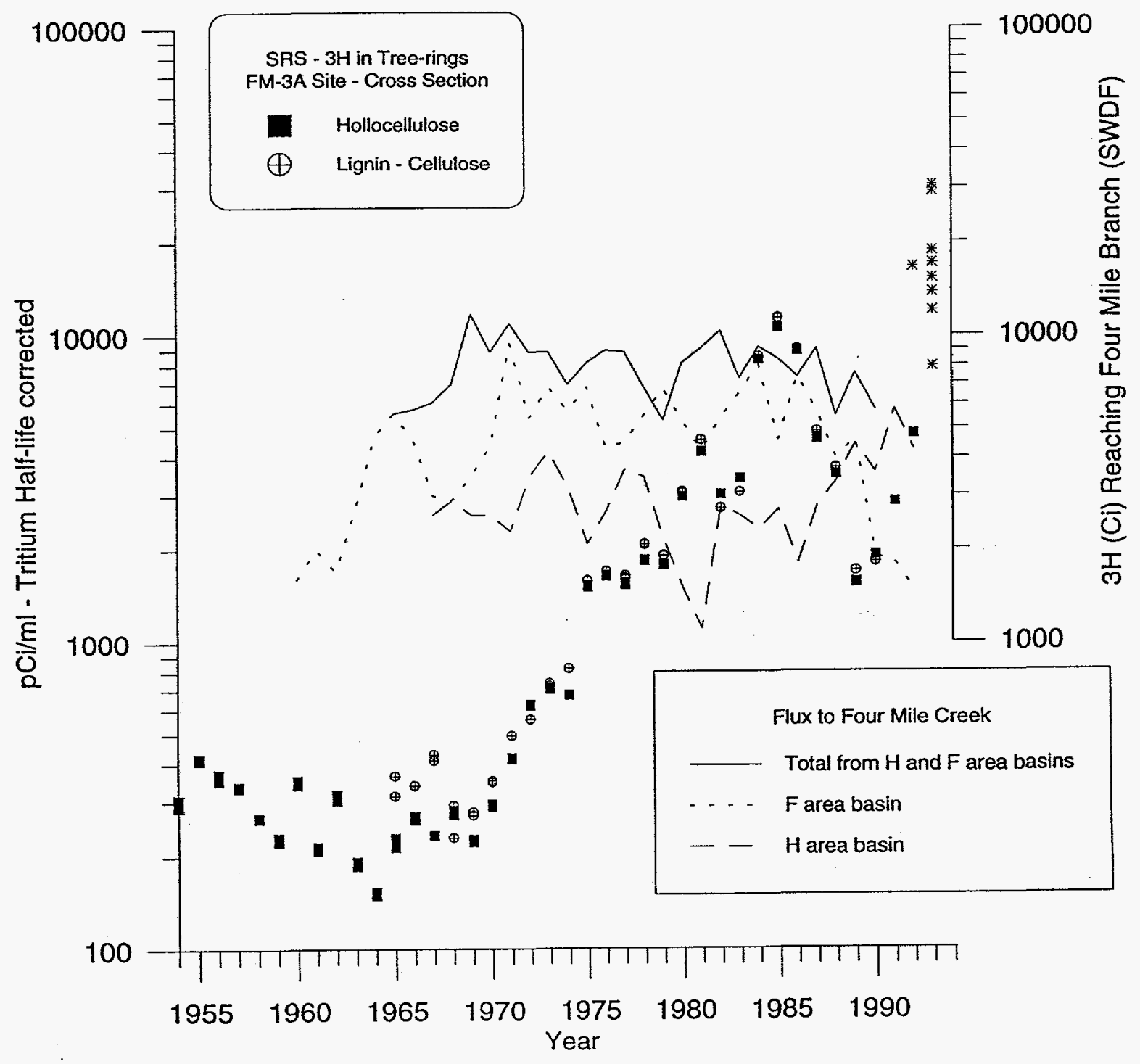

Figure 7. Relationship between tritium in tree-rings (corrected for radioactive decay) and tritium release to Four Mile Creek from the $\mathrm{F}$ and $\mathrm{H}$ seepage basin. 
Figure 8 shows the relationship between the reconstructed tritium release from the Solid Waste Disposal Facility (SWDF) to Four Mile Creek and the tritium concentrations reconstructed from tree-rings. The tritium content in cellulose of annual tree-rings appears to correlate well with observed tritium releases from the SWDF. Extending this interpretation to the period before 1979 suggests that tritium flux from the SWDF to Four Mile creek increased after 1970. Assuming the concentration of tritium in tree-rings represent tritium concentrations in groundwater, the results in Figure 8 suggest that the plume of tritium groundwater can be reconstructed by using this technique on a number of trees over a wide area. Expanded study of groundwater tritium movement is warranted with this method. 


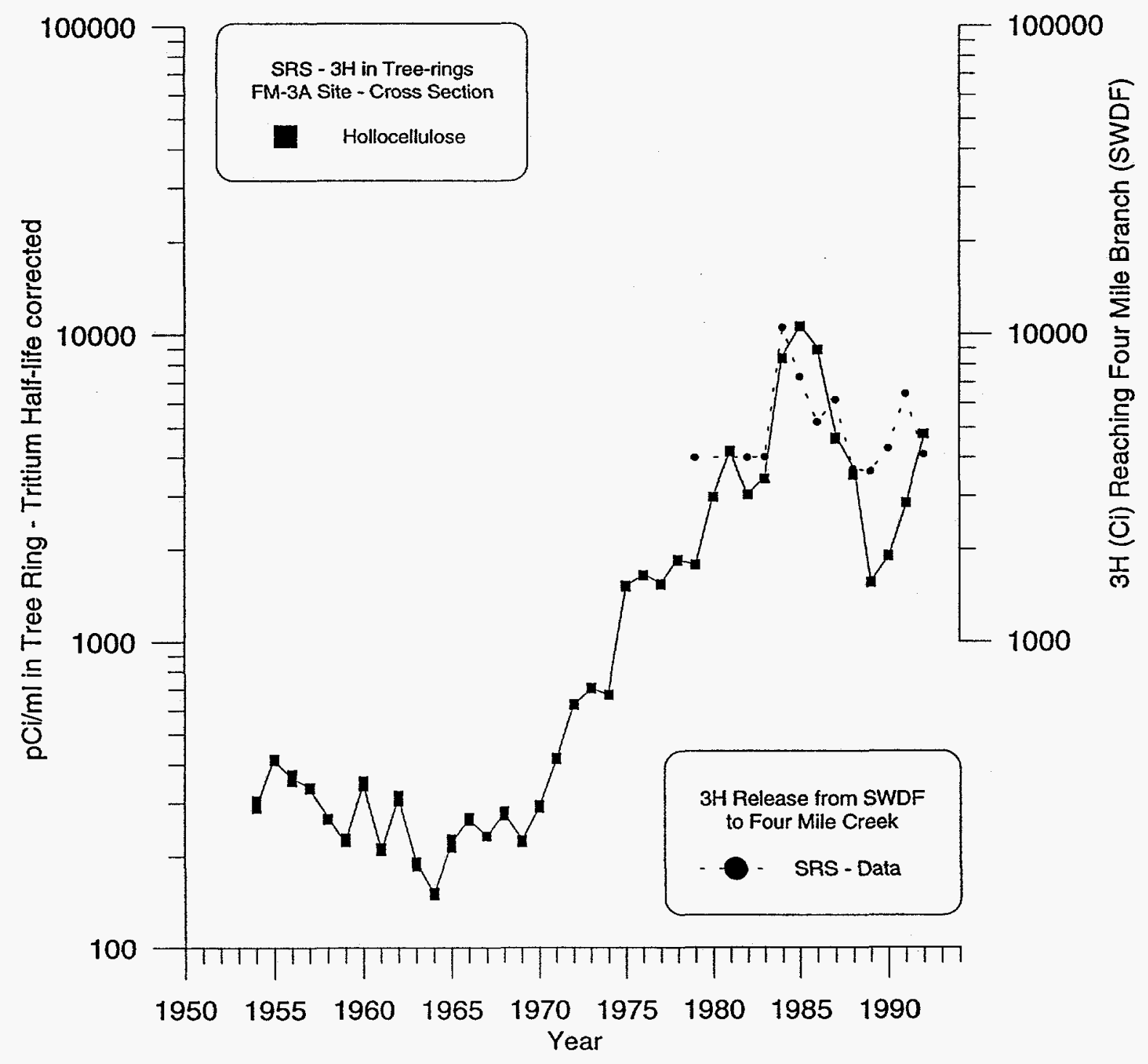

Figure 8. Relationship between tritium in tree-rings (corrected for radioactive decay) and reconstructed tritium release to Four Mile Creek from the Solid Waste Deposit Facility. 


\section{X-Ray Fluorescence Methods and Results}

Annual tree-ring samples were separated and ground to ca. 1-2mm size fractions in a Whiley Mill, no chemical treatment was performed on these samples. Ten grams of this ground material was pressed in a Spex 1.25 inch pellet die at 23,000lbs (10 tons/sp in.). The resulting pellet was desiccated and analyzed in a Kevex $770 \mathrm{X}$-Ray Fluorescence (XRF) instrument. Each element has a unique set of $\mathrm{x}$-ray emissions that allow for detection and quantification of the abundance of each element in the tree-ring sample. Each sample was analyzed twice. The first analysis using an iron secondary target at 20 $\mathrm{KV}$ and $0.7 \mathrm{~mA}, 50 \%$ dead-time for 2000 seconds for analysis of the light elements. The second analysis using a zirconium secondary target at $30 \mathrm{KV}$ and $2.2 \mathrm{~mA}, 50 \%$ dead-time for 16,000 seconds for analysis of trace metal elements, in particular $\mathrm{Pb}$. A gaussian peak-fitting routine was used to separate overlapping peaks and to determine the counts per second (CPS) of each elemental peak. A pure cellulose sample was run as a sample blank. The CPS for each element is to be compared with NIST \#1575 Pine Needle standard to determine concentration.

The results of XRF analysis of annual tree-rings from the SRS cross-section are listed in Table $2 \mathrm{a}$ and $2 \mathrm{~b}$. Any sample within $33 \%$ of the blank was considered to be below the maximum detectable limit (MDL) and thus are reported as below detection (BD). Repeat analysis of a few samples suggest that this method is useful for simple and rapid analysis of annual changes in trace elements in tree-rings.

Figure 9 presents the temporal changes in the trace element concentration of the cross-section sample during the period 1960 - 1993 represented by XRF. It is interesting to note the striking change in calcium concentration during the period of interest. This change may represent a natural physiological change in the tree or may represent a change in the concentration of calcium in the root zone. Lead is below detection until the mid1960 's, then falls below detection in the early-1980's. The appearance of lead may represent an increasing anthropogenic human influence (leaded gasoline, air pollution from Augusta and Savannah), and the decline below detection may represent the decreased use of lead and subsequent decrease in environmental lead concentrations. 

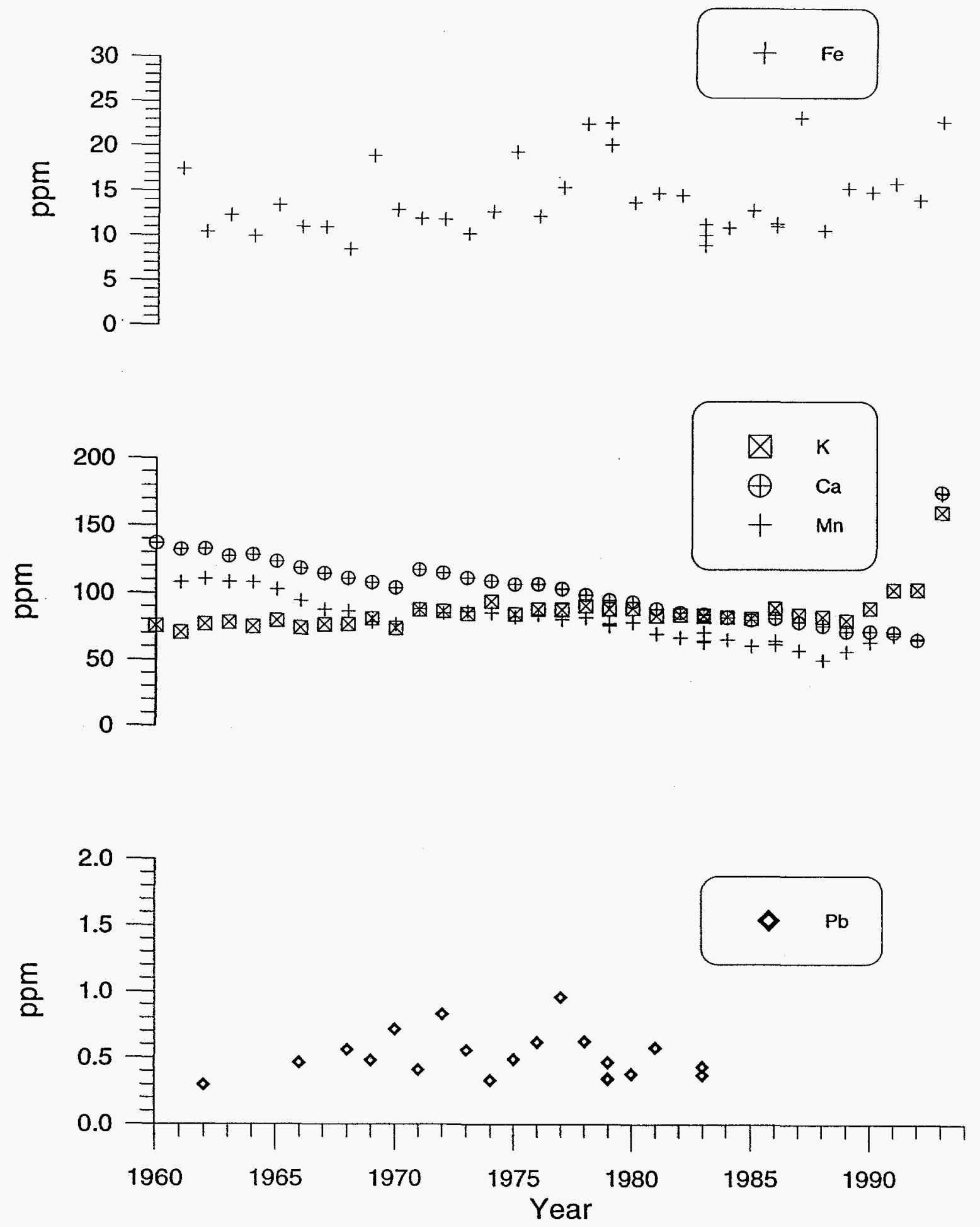

Figure 9. Parts per million of selected trace elements in annual rings of cross-section as measured by XRF. No chemical treatment has been applied to samples. Results have been normalized to the countrate of a pure cellulose sample. 
The results of XRF testing are not conclusive and are presented to show the potential of using tree-ring trace element analysis for the reconstruction of trace element contamination of soils and groundwater in and around hazardous waste sites and landfills.

\section{Gamma-ray Spectrometry Methods and Results}

Dried samples of annual tree-rings from the cross-section supplied by SRS were ground to 1 - $2 \mathrm{~mm}$ size fraction. Prior to any chemical treatment, a 1 liter gammaspectrometry sample chamber was filled with the ground sample and the weight recorded. Each annual ring from 1960 - 1993 and the bark of the cross-section were counted following routine CAIS QA/QC procedures. A chemical blank of pure cellulose (XRF flux) was counted in the same manner. The results of the gamma-spectrometry measurements are found in Table 3.

Figure 10 presents the temporal changes in eight radioisotopes as measured with gamma spectrometry. Note that after background subtraction some of the countrates were below the countrate of the blank cellulose sample. Much of the variability in radionuclide activity is within the uncertainty of the measurement and therefore, interpretation of the data is difficult. Successful study of radionuclide variability in the annual rings of trees at the SRS would require larger sample size or physical/chemical treatments of the samples. 


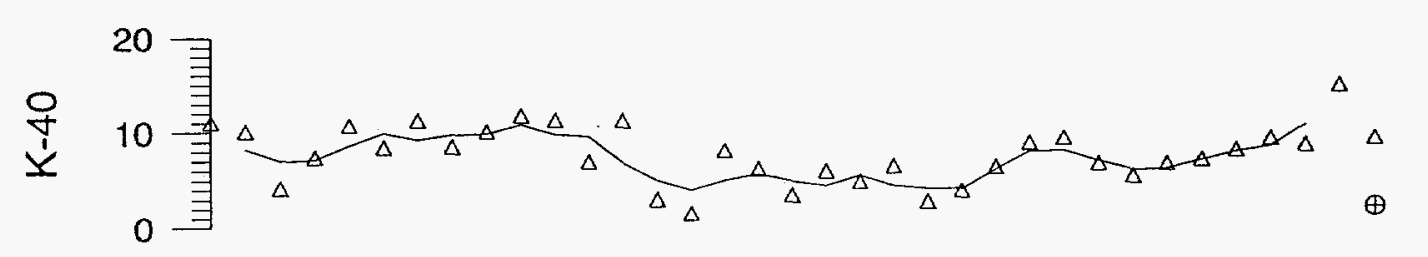

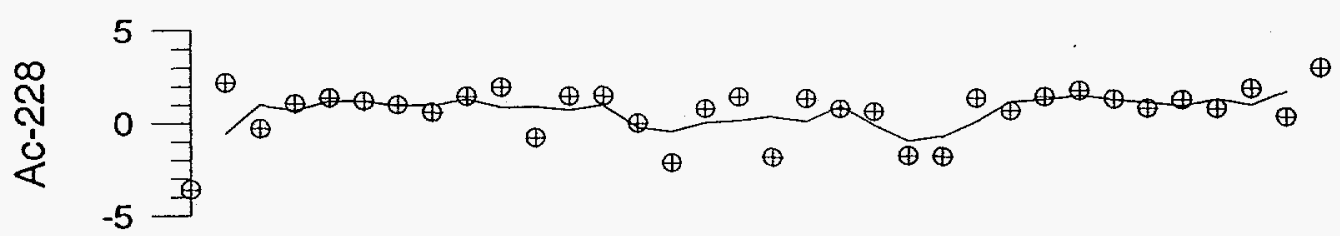

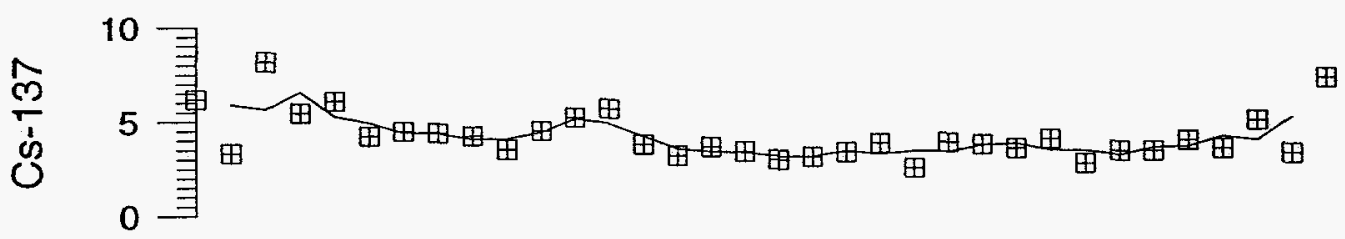

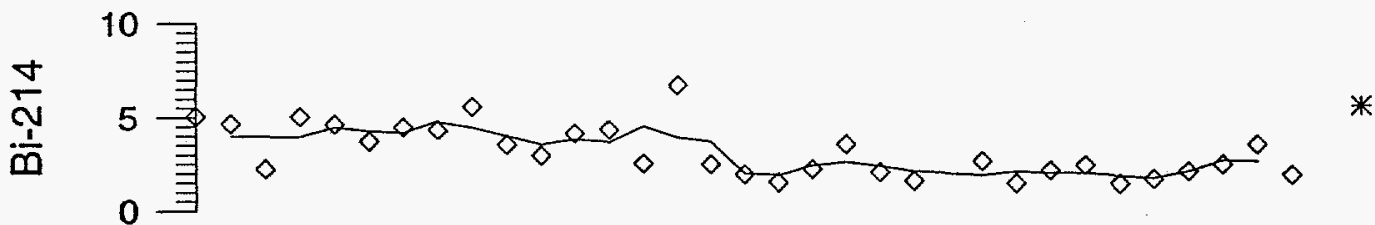

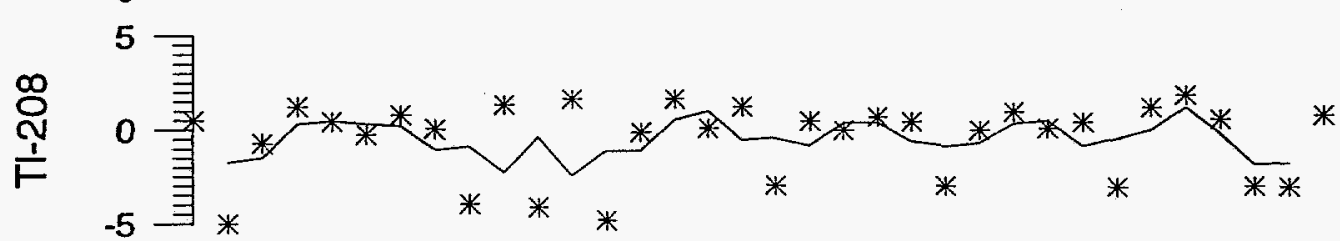

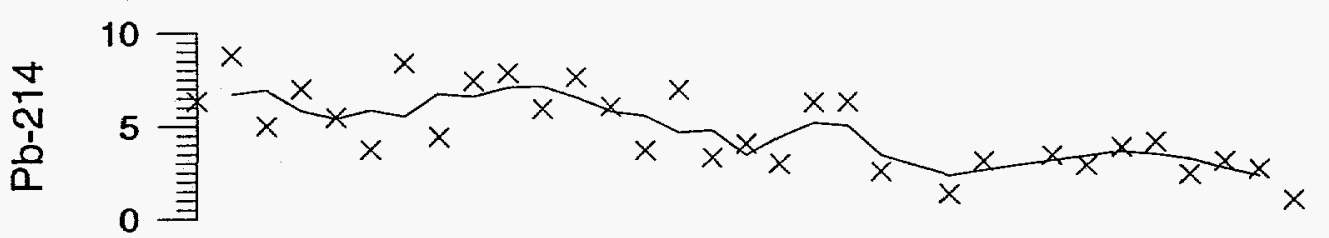

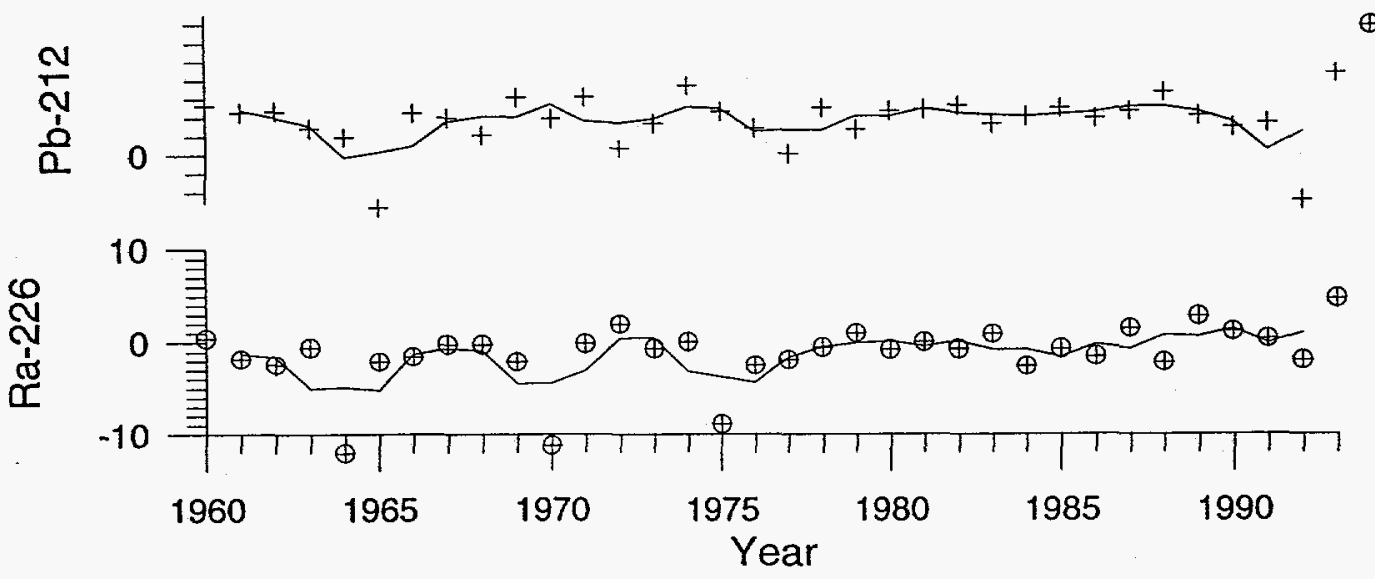

Figure 10. Countrate $(\mathrm{cpm} / 100 \mathrm{gm})$ of gamma-ray spectrometer for annual rings of crosssection provided by SRS. No chemical treatment has been applied to samples. Results have been normalized to the countrate of a pure cellulose sample. 


\section{Conclusions}

The results of this study showed the feasibility of measuring tritium values in annual rings from trees collected at the SRS in order to date the history and relative concentration of tritium. The concentration of tritium in tree-rings from the pilot study site near the SDWF effectively differentiated the flux of tritium reaching the Four Mile creek and can provide a methodology for rapid, cost effective means of future monitoring of groundwater contaminant plumes resulting from accidental radionuclide releases.

Variations in the annual tree ring concentration of radionuclides as measured by gamma-spectrometry did not show significant results. Sample size may be the limiting factor for this methodology. Investigation of variations in trace element concentration in annual tree rings using X-Ray Fluorescence methodology did show promise as a rapid and cost effective technique for reconstructing the levels of environmental metal contamination. A more detailed study is needed to prove this method. 
References

Carlton, W.H., A.G.Evans, C.E. Murphy Jr., and D.M. Tuch, 1993, Assessment of Radiocarbon in the Savannah River Site Environment. Westinghouse Savannah River Company, WSRC-TR-93-215.

Kozak, K., B. Obelic and N. Horvanticic, 1989, Tritium and 14C in tree rings of the last three decades. In Long, A., R.S. Kra and D. Srdoc, eds., Proceedings of the 13 th Internation Radiocarbon Conference: Radiocarbon 31:3 766-770

Momoshima, N. Y. Takashima, H. Hakozaki and T. Okai, 1990, Tritium in the environment: monitoring methods for the distribution of various chemical forms. Proceedings of the 4th Intemational Seminar for Liquid Scintillation Analysis, Tokyo Japan, June 5-6 108-125

Murphy, C.E. Jr., L.R. Bauer, D.W. Hayes, W.L. Marter, C.C. Zeigler, D.E. Stephenson, D.D. Hoel and D.M. Hamby, 1991. Tritium in the Savannah River Site Environment . Westinghouse Savannah River Company, WSRC-RP-90-424-1, Revision 1. 
Appendix 1. Quantulus $Q A / Q C$ data collection file: Registry.txt.

DIRECTORY PATH :08-26-94.SRS ** *

PARAMETER GROUP: 1

ID: $3 \mathrm{H}$ COUNTING 3ML

OOA PROGRAM MODE

$6 \rightarrow$

$\begin{array}{crl}\text { ORDER } & \text { POS } & \text { ID } \\ 1 & 1 & 1975 \\ 2 & 2 & 1976 \\ 3 & 3 & 1977 \\ 4 & 4 & 1978 \\ 5 & 5 & 1979 \\ 6 & 6 & 1980 \\ 7 & 7 & 1981 \\ 8 & 8 & 1982 \\ 9 & 9 & 1983 \\ 10 & 10 & 1984 \\ 11 & 11 & 1985 \\ 12 & 12 & 1986 \\ 13 & 13 & 1987 \\ 14 & 14 & 1988 \\ 15 & 15 & 1989 \\ 16 & 16 & 1990 \\ 17 & 20 & \text { BKG }\end{array}$

NUMBER OF CYCIES

COINCIDENCE BIAS
CTIME COUNTS CUCNTS MCW REP

100:00 NO LIM NO IIM

100:00 NO LIM NO IIM

100:00 NO LIM NO LIM

100:00 NO LIM NO IIM

100:00 NO IIM NO IIM

100:00 NO LIM NO LIM

100:00 NO IIM NO IIM

100:00 NO LIM NO LIM

100:00 NO LIM NO LIM

100:00 NO IIM NO LIM

100:00 NO LIM NO IIM

100:00 NO LIM NO IIM

100:00 NO LIM NO IIM

100:00 NO LIM NO LIM

100:00 NO LIM NO LIM

100:00 NO LIM NO IIM

100:00 NO LIM NO IIM

$\begin{array}{rr}1 & 1 \\ 1 & 1 \\ 1 & 1 \\ 1 & 1 \\ 1 & 1 \\ 1 & 1 \\ 1 & 1 \\ 1 & 1 \\ 1 & 1 \\ 1 & 1 \\ 1 & 1 \\ 1 & 1 \\ 1 & 1 \\ 1 & 1 \\ 1 & 1 \\ 1 & 1 \\ 1 & 1\end{array}$

STD STMS STIME

N

$\mathrm{N}$

N

N

N

N

$\mathrm{N}$

N

N

N

N

N

N

N

$\mathrm{N}$

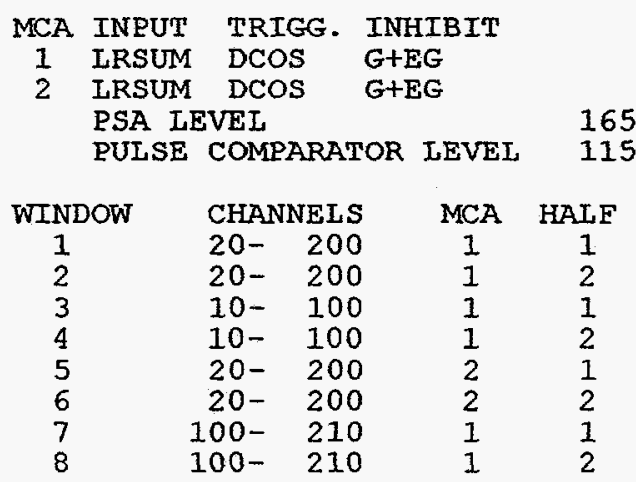

MEMORY SPIIT

PAC

PSA

selected printout for terminal 1 (A)

1.2 .3$.

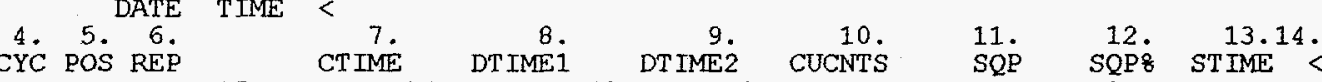
CYC POS REP

15.

23. CT IME

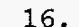
16. CPM1 COUNTS1 COUNTS3

32 .

31.

CPM5

39.

CPM7
Counts 5

41.

COUNTS7

Selected printout for terminal 2 (B)

CYC POS REP

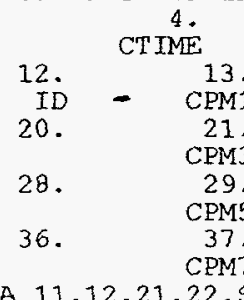

SEND SPECTRA $11,12,21,22, \mathrm{~S}$

5.

5 .

\begin{tabular}{rrr} 
MEE & DTIME2 & \multicolumn{1}{l}{ CUCNTS } \\
14. & 15. & 16. \\
COUNTS1 & CPM1. & CPM2 \\
22. & 23. & 24. \\
COUNTS3 & CPM38 & CPM4 \\
30. & 31. & 32. \\
COUNTS5 & CPM58 & CPM6 \\
38. & 39. & 40. \\
COUNTS7 & CPM78 & CPM8
\end{tabular}

$$
\begin{aligned}
& 19 . \\
& \text { CPM2 } \\
& 27 . \\
& \text { CPM4 } \\
& 35 . \\
& \text { CPM6 } \\
& 43 .
\end{aligned}
$$ COUNTS2 28. COUNT'S 36.
COUNTS6
44.
COUNTSB

21.22 . CPM28 $<$ CPM4 8

37.38 . CPM6: $<$

45.

CPM8:

RESOLUTION OF SPECTRA 1024 
LIST ING

INSTRUMENT NUMBER

$Y$

CYC POS REP

CTIME DTIME1 DTIME2 CUCNTS SQP SQP8 STIME

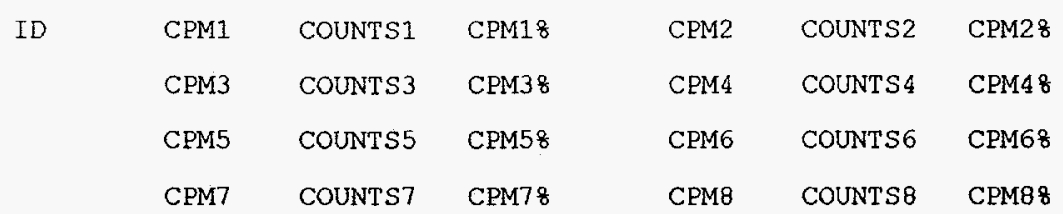

Q010101N.001 10 APR 1984 18:43

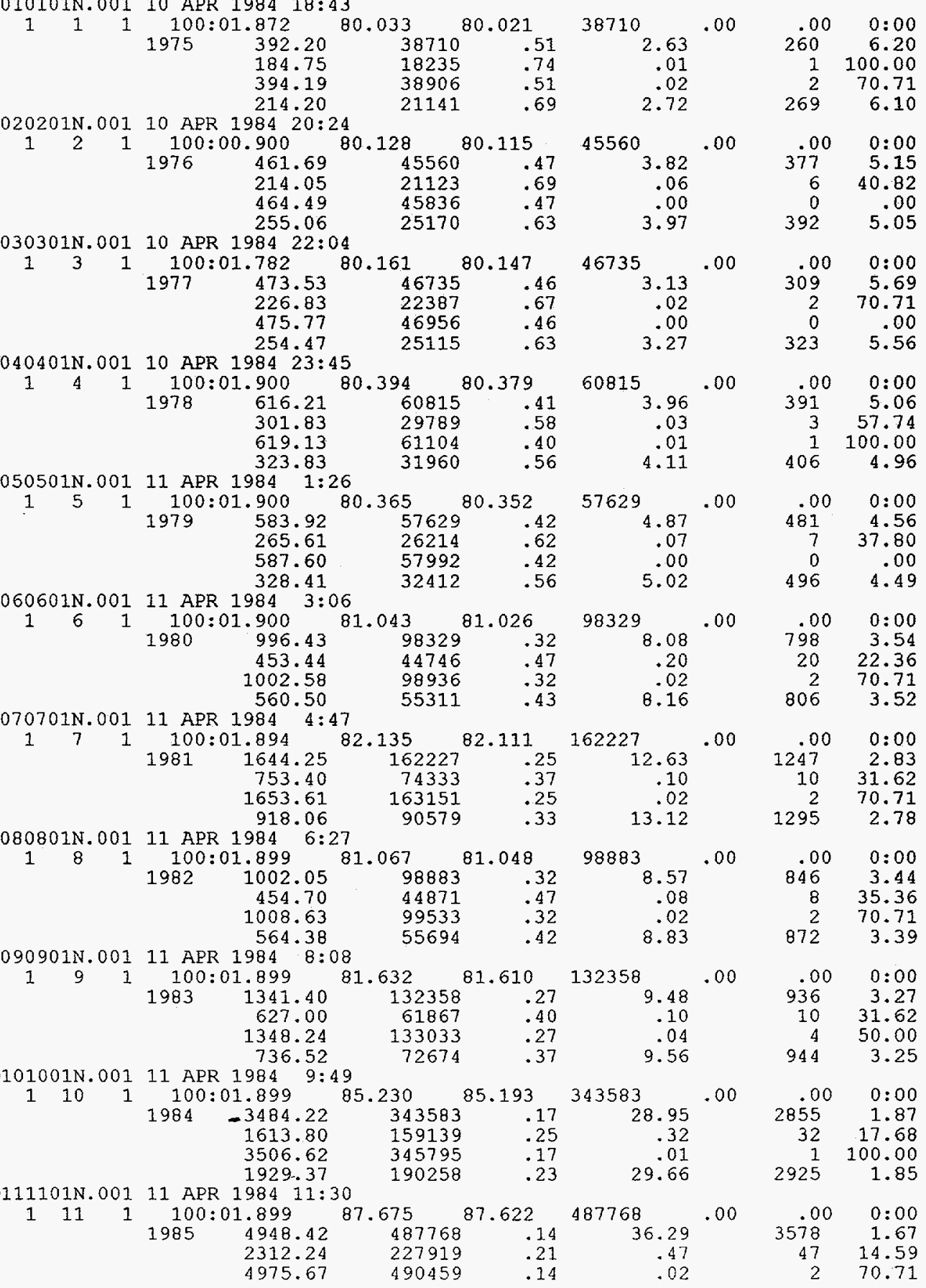




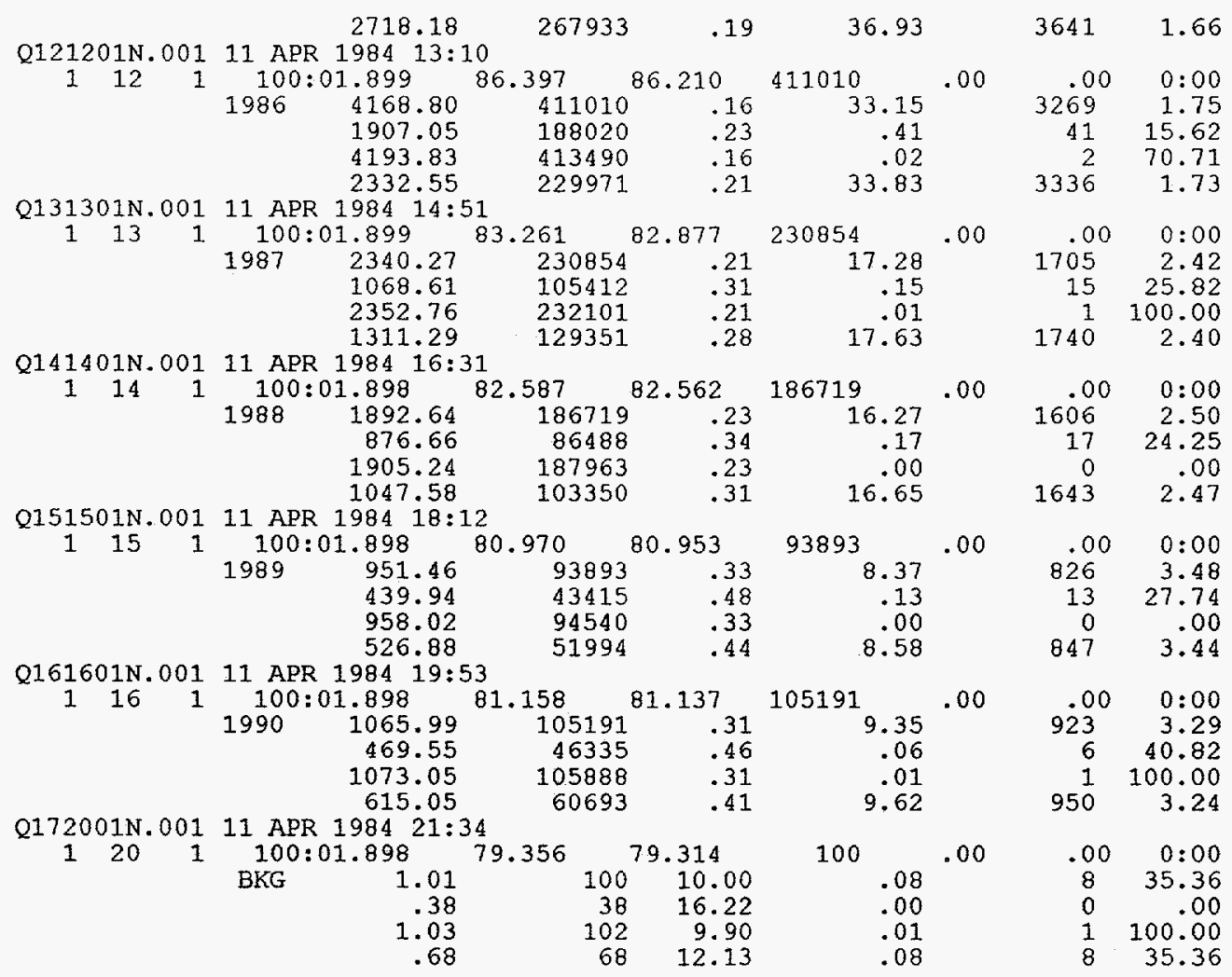


Table 1a. Results of LSC counting Tritium - first bleach treatment of cross-section wood.

\begin{tabular}{|c|c|c|c|c|c|c|}
\hline Year & cpm-A & cpm-B & Wt (gms) & $\mathrm{cpm} / \mathrm{gm}$ & $\begin{array}{l}\text { A/B } \\
\text { Ratio }\end{array}$ & $\begin{array}{l}\mathrm{t}^{1 / 2} \text {-corr } \\
\left(\mathrm{pCi} / 1^{3} \mathrm{H}\right)\end{array}$ \\
\hline 1965 & 53.1 & 25.33 & 0.98 & 54.18367 & 2.096328 & 273.0178 \\
\hline 1965 & 45.69 & 21.28 & 0.98 & 46.62245 & 2.147086 & 234.9188 \\
\hline 1966 & 48.89 & 22.03 & 0.92 & 53.1413 & 2.219246 & 253.2426 \\
\hline 1966 & 49.15 & 22.32 & 0.92 & 53.42391 & 2.202061 & 254.5894 \\
\hline 1967 & 66.73 & 31.55 & 0.94 & 70.98936 & 2.115056 & 319.9483 \\
\hline 1967 & 64.08 & 28.79 & 0.94 & 68.17021 & 2.225773 & 307.2424 \\
\hline 1968 & 49.76 & 22.94 & 0.97 & 51.29897 & 2.169137 & 218.6639 \\
\hline 1968 & 39.06 & 18.23 & 0.97 & 40.26804 & 2.142622 & 171.6441 \\
\hline 1969 & 48.92 & 21.71 & 0.97 & 50.43299 & 2.25334 & 203.313 \\
\hline 1969 & 50.07 & 23.07 & 0.97 & 51.61855 & 2.170351 & 208.0924 \\
\hline 1970 & 66.98 & 30.24 & 0.97 & 69.05154 & 2.214947 & 263.2727 \\
\hline 1970 & 65.94 & 29.6 & 0.97 & 67.97939 & 2.227703 & 259.1849 \\
\hline 1971 & 96.82 & 44.45 & 0.95 & 101.9158 & 2.178178 & 367.4989 \\
\hline 1971 & 97.39 & 45.08 & 0.95 & 102.5158 & 2.160382 & 369.6624 \\
\hline 1972 & 118.47 & 54.63 & 0.97 & 122.134 & 2.168589 & 416.5173 \\
\hline 1972 & 118.13 & 53.93 & 0.97 & 121.7835 & 2.190432 & 415.322 \\
\hline 1973 & 160.55 & 75.95 & 0.97 & 165.5155 & 2.113891 & 533.8474 \\
\hline 1973 & 164.13 & 77.06 & 0.97 & 169.2062 & 2.129899 & 545.7512 \\
\hline 1974 & 194.87 & 87.84 & 0.98 & 198.8469 & 2.218465 & 606.5676 \\
\hline 1974 & 194.99 & 88.43 & 0.98 & 198.9694 & 2.205021 & 606.9413 \\
\hline 1975 & 392.2 & 184.75 & 0.97 & 404.3299 & 2.122869 & 1166.483 \\
\hline 1976 & 461.69 & 214.69 & 1.01 & 457.1188 & 2.150496 & 1247.25 \\
\hline 1977 & 473.53 & 226.83 & 1.03 & 459.7379 & 2.087599 & 1186.36 \\
\hline 1978 & 616.21 & 301.83 & 0.99 & 622.4344 & 2.04158 & 1519.084 \\
\hline 1979 & 583.92 & 265.61 & 0.96 & 608.25 & 2.198411 & 1403.953 \\
\hline 1980 & 996.43 & 453.44 & 0.96 & 1037.948 & 2.19749 & 2265.833 \\
\hline 1981 & 1644.25 & 753.4 & 1.01 & 1627.97 & 2.18244 & 3361.094 \\
\hline 1982 & 1002.05 & 454.7 & 0.98 & 1022.5 & 2.203761 & 1996.547 \\
\hline 1983 & 1341.4 & 627 & 1.1 & 1219.455 & 2.139394 & 2251.977 \\
\hline 1984 & 3484.22 & 1613.8 & 0.97 & 3591.979 & 2.159016 & 6273.559 \\
\hline 1985 & 4948.42 & 2312.24 & 0.98 & 5049.408 & 2.140098 & 8340.703 \\
\hline 1986 & 4168.8 & 1907.05 & 0.98 & 4253.877 & 2.185994 & 6645.522 \\
\hline 1987 & 2340.27 & 1068.61 & 0.97 & 2412.649 & 2.190013 & 3564.678 \\
\hline 1988 & 1892.64 & 876.66 & 0.98 & 1931.265 & 2.158921 & 2698.671 \\
\hline 1989 & 951.46 & 439.94 & 1.01 & 942.0396 & 2.162704 & 1244.971 \\
\hline 1990 & 1065.99 & 469.55 & 1 & 1065.99 & 2.270237 & 1332.371 \\
\hline
\end{tabular}


Table $1 \mathrm{~b}$. LSC results of tritium in Hollocellulose fraction of annual tree-rings.

\begin{tabular}{|c|c|c|c|c|c|c|}
\hline Year & cpm-A & cpm-B & Wt (gms) & $\mathrm{cpm} / \mathrm{gm}$ & $\begin{array}{l}\text { A/B } \\
\text { Ratio }\end{array}$ & $\begin{array}{l}\mathrm{t}^{\mathrm{l} / 2}-\operatorname{corr} \\
\left(\mathrm{pCi} / \mathrm{l}^{3} \mathrm{H}\right)\end{array}$ \\
\hline 1954 & 23.91 & 10.82 & 0.97 & 23.77795 & 2.312331 & 301.2839 \\
\hline 1954 & 24.31 & 10.98 & 0.97 & 24.19032 & 2.315294 & 306.5089 \\
\hline 1954 & 22.9 & 10.29 & 0.97 & 22.73672 & 2.335152 & 288.0906 \\
\hline 1955 & 33.84 & 15.91 & 0.96 & 34.36939 & 2.190206 & 411.8654 \\
\hline 1955 & 34.17 & 15.46 & 0.96 & 34.71314 & 2.280225 & 415.9846 \\
\hline 1955 & 34.39 & 15.53 & 0.96 & 34.94231 & 2.284337 & 418.7309 \\
\hline 1956 & 31.07 & 14.32 & 0.94 & 32.15385 & 2.243078 & 364.4168 \\
\hline 1956 & 30.06 & 13.81 & 0.94 & 31.07938 & 2.253412 & 352.2392 \\
\hline 1956 & 31.79 & 14.25 & 0.94 & 32.9198 & 2.308505 & 373.0978 \\
\hline 1957 & 31.74 & 15.1 & 0.98 & 31.52512 & 2.167341 & 337.9124 \\
\hline 1957 & 31.78 & 15.07 & 0.98 & 31.56593 & 2.174724 & 338.3499 \\
\hline 1957 & 31.34 & 14.35 & 0.98 & 31.11695 & 2.258088 & 333.5374 \\
\hline 1958 & 25.63 & 11.85 & 0.95 & 26.08907 & 2.252202 & 264.4771 \\
\hline 1958 & 25.76 & 11.67 & 0.95 & 26.22591 & 2.301663 & 265.8643 \\
\hline 1958 & 25.91 & 12.15 & 0.95 & 26.38381 & 2.217202 & 267.465 \\
\hline 1959 & 22.93 & 10.06 & 0.95 & 23.24696 & 2.396694 & 222.8834 \\
\hline 1959 & 23.67 & 10.56 & 0.95 & 24.02591 & 2.349513 & 230.3516 \\
\hline 1959 & 23.55 & 10.54 & 0.95 & 23.89959 & 2.341982 & 229.1405 \\
\hline 1960 & 37.64 & 16.98 & 0.94 & 39.14321 & 2.280477 & 354.9358 \\
\hline 1960 & 36.12 & 16.37 & 0.94 & 37.52618 & 2.272173 & 340.2733 \\
\hline 1960 & 36.28 & 16.62 & 0.94 & 37.6964 & 2.246306 & 341.8167 \\
\hline 1961 & 26.09 & 11.68 & 1.04 & 24.27367 & 2.329996 & 208.1665 \\
\hline 1961 & 26.84 & 12.59 & 1.04 & 24.99482 & 2.213322 & 214.351 \\
\hline 1961 & 26.52 & 12.11 & 1.04 & 24.68713 & 2.279227 & 211.7123 \\
\hline 1962 & 39.3 & 17.2 & 0.98 & 39.2394 & 2.3513 & 318.2584 \\
\hline 1962 & 39 & 17.85 & 0.98 & 38.93328 & 2.24378 & 315.7755 \\
\hline 1962 & 37.44 & 16.57 & 0.98 & 37.34144 & 2.327219 & 302.8646 \\
\hline 1963 & 23.87 & 10.62 & 0.94 & 24.49427 & 2.355552 & 187.8901 \\
\hline 1963 & 24.44 & 10.89 & 0.94 & 25.10065 & 2.348981 & 192.5416 \\
\hline 1963 & 23.55 & 10.98 & 0.94 & 24.15384 & 2.240304 & 185.2788 \\
\hline 1964 & 23.63 & 10.87 & 1.08 & 21.09686 & 2.272867 & 153.0521 \\
\hline 1964 & 23.05 & 10.23 & 1.08 & 20.55983 & 2.366066 & 149.1561 \\
\hline 1964 & 23.09 & 10.7 & 1.08 & 20.59686 & 2.257279 & 149.4248 \\
\hline 1965 & 30.41 & 13.79 & 0.91 & 32.48859 & 2.283931 & 222.9124 \\
\hline 1965 & 31.22 & 14.32 & 0.91 & 33.3787 & 2.25421 & 229.0197 \\
\hline 1965 & 29.16 & 13.32 & 0.91 & 31.11496 & 2.269779 & 213.4876 \\
\hline 1966 & 41.93 & 18.82 & 1.01 & 40.67784 & 2.285702 & 263.9632 \\
\hline 1966 & 42.83 & 19.11 & 1.01 & 41.56893 & 2.298686 & 269.7455 \\
\hline 1966 & 41.67 & -19.02 & 1.01 & 40.42041 & 2.246243 & 262.2927 \\
\hline 1967 & 35.48 & 15.64 & 0.91 & 38.06002 & 2.341028 & 233.5804 \\
\hline 1967 & 35.44 & 15.5 & 0.91 & 38.01606 & 2.360663 & 233.3106 \\
\hline 1967 & 35.38 & 16.07 & 0.91 & 37.95013 & 2.268341 & 232.906 \\
\hline
\end{tabular}


Table 1b. cont.

\begin{tabular}{|c|c|c|c|c|c|c|}
\hline Year & cpm-A & cpm-B & Wt (gms) & $\mathrm{cpm} / \mathrm{gm}$ & $\begin{array}{l}\text { A/B } \\
\text { Ratio }\end{array}$ & $\begin{array}{l}\mathrm{t}^{1 / 2}-\operatorname{corr} \\
\left(\mathrm{pCi} / \mathrm{l}^{3} \mathrm{H}\right)\end{array}$ \\
\hline 1968 & 46.12 & 20.22 & 0.93 & 48.68238 & 2.336801 & 282.5669 \\
\hline 1968 & 44.49 & 20.24 & 0.93 & 46.9297 & 2.250347 & 272.3938 \\
\hline 1968 & 45.06 & 19.73 & 0.93 & 47.5426 & 2.341304 & 275.9513 \\
\hline 1969 & 35.56 & 15.9 & 0.85 & 40.84072 & 2.305912 & 224.1945 \\
\hline 1969 & 35.98 & 15.94 & 0.85 & 41.33484 & 2.327626 & 226.9069 \\
\hline 1969 & 35.17 & 15.01 & 0.85 & 40.3819 & 2.423265 & 221.6758 \\
\hline 1970 & 51.61 & 22.47 & 0.89 & 57.03889 & 2.347538 & 296.1315 \\
\hline 1970 & 50.37 & 22.48 & 0.89 & 55.64563 & 2.289138 & 288.898 \\
\hline 1970 & 50.33 & 22.7 & 0.89 & 55.60069 & 2.264264 & 288.6647 \\
\hline 1971 & 77.79 & 33.86 & 0.91 & 84.55452 & 2.330623 & 415.1761 \\
\hline 1971 & 77.98 & 33.94 & 0.91 & 84.76331 & 2.33073 & 416.2013 \\
\hline 1971 & 79.05 & 34.5 & 0.91 & 85.93914 & 2.323741 & 421.9748 \\
\hline 1972 & 130.71 & 60.78 & 0.96 & 135.2757 & 2.166772 & 628.1988 \\
\hline 1972 & 131.43 & 60.27 & 0.96 & 136.0256 & 2.197484 & 631.6816 \\
\hline 1972 & 129.82 & 60.31 & 0.96 & 134.3486 & 2.168931 & 623.8936 \\
\hline 1973 & 160.62 & 72.9 & 0.99 & 161.3885 & 2.21741 & 708.8136 \\
\hline 1973 & 159.84 & 70.95 & 0.99 & 160.6006 & 2.267962 & 705.3533 \\
\hline 1974 & 171.58 & 78.56 & 1.05 & 162.6044 & 2.196944 & 675.4198 \\
\hline 1974 & 170.83 & 78.56 & 1.05 & 161.8901 & 2.187293 & 672.4528 \\
\hline 1975 & 370.13 & 170.88 & 0.96 & 384.6715 & 2.17182 & 1511.171 \\
\hline 1975 & 374.45 & 173.71 & 0.96 & 389.1715 & 2.161256 & 1528.849 \\
\hline 1975 & 374.12 & 173.91 & 0.96 & 388.8277 & 2.156851 & 1527.498 \\
\hline 1976 & 451.55 & 207.01 & 1.02 & 441.8673 & 2.18614 & 1641.713 \\
\hline 1976 & 454.51 & 206.22 & 1.02 & 444.7693 & 2.208961 & 1652.495 \\
\hline 1976 & 452.9 & 207.63 & 1.02 & 443.1908 & 2.186113 & 1646.631 \\
\hline 1977 & 449.2 & 210.87 & 1.02 & 439.5634 & 2.134772 & 1544.575 \\
\hline 1977 & 446.79 & 205.94 & 1.02 & 437.2006 & 2.174336 & 1536.272 \\
\hline 1978 & 547.68 & 245.21 & 0.99 & 552.3582 & 2.237782 & 1835.652 \\
\hline 1978 & 552.72 & 247.39 & 0.99 & 557.4491 & 2.238437 & 1852.57 \\
\hline 1979 & 577.39 & 268.32 & 1.02 & 565.2399 & 2.155512 & 1776.578 \\
\hline 1979 & 580.27 & 269.58 & 1.02 & 568.0634 & 2.156122 & 1785.452 \\
\hline 1980 & 989.02 & 455.89 & 0.99 & 998.1562 & 2.171599 & 2967.099 \\
\hline 1980 & 991.04 & 451.74 & 0.99 & 1000.197 & 2.196067 & 2973.164 \\
\hline 1981 & 1497.37 & 678.87 & 1.01 & 1481.708 & 2.207183 & 4165.604 \\
\hline 1981 & 1512.18 & 685.71 & 1.01 & 1496.371 & 2.206764 & 4206.828 \\
\hline 1982 & 1148.08 & 519.91 & 1.01 & 1135.876 & 2.210196 & 3020.149 \\
\hline 1982 & 1151.89 & 519.67 & 1.01 & 1139.648 & 2.218562 & 3030.179 \\
\hline 1983 & 1341.26 & 612.64 & 0.99 & 1353.954 & 2.190955 & 3404.736 \\
\hline 1983 & 1344.97 & -612.39 & 0.99 & 1357.702 & 2.197917 & 3414.159 \\
\hline 1984 & 3696.01 & 1696.61 & 1.05 & 3519.205 & 2.179055 & 8369.625 \\
\hline 1984 & 3688.04 & 1692.93 & 1.05 & 3511.614 & 2.179084 & 8351.573 \\
\hline
\end{tabular}


Table 1b. cont.

$\begin{array}{lllllll}\text { Year } & \text { cpm-A } & \text { cpm-B } & \text { Wt }(\mathrm{gms}) & \begin{array}{l}\text { cpm/gm } \\ \text { A/B }\end{array} & \begin{array}{l}t^{1 / 2} \text {-corr } \\ \text { Ratio }\end{array} & \begin{array}{l}\text { (pCi// } \\ \text { H } H)\end{array} \\ 1985 & 4761.86 & 2189.89 & 1.01 & 4713.876 & 2.174928 & 10602.83 \\ 1986 & 4775.66 & 2209.22 & 1.01 & 4727.54 & 2.16214 & 10633.56 \\ 1986 & 4222.93 & 1934.69 & 1.01 & 4187.945 & 2.195277 & 8930.223 \\ 1987 & 2370.28 & 1095.4 & 1.04 & 2278.303 & 2.164748 & 4583.729 \\ 1987 & 2399.49 & 1096.49 & 1.04 & 2306.389 & 2.189254 & 4640.236 \\ 1988 & 1803.96 & 857.9 & 0.98 & 1839.913 & 2.10385 & 3500.957 \\ 1988 & 1817.46 & 867.45 & 0.98 & 1853.688 & 2.096244 & 3527.169 \\ 1989 & 810.93 & 380.41 & 0.93 & 871.0587 & 2.134247 & 1567.541 \\ 1989 & 804.61 & 376.21 & 0.93 & 864.263 & 2.14129 & 1555.312 \\ 1990 & 1001.13 & 441.42 & 0.89 & 1123.915 & 2.270409 & 1912.877 \\ 1990 & 994.32 & 436.75 & 0.89 & 1116.264 & 2.27911 & 1899.854 \\ 1990 & 994.02 & 438.02 & 0.89 & 1115.927 & 2.271803 & 1899.281 \\ 1991 & 1665 & 744.86 & 0.94 & 1770.377 & 2.236723 & 2849.714 \\ 1991 & 1664.64 & 747.12 & 0.94 & 1769.994 & 2.229467 & 2849.098 \\ 1991 & 1659.85 & 745.22 & 0.94 & 1764.899 & 2.228723 & 2840.896 \\ 1992 & 3011.72 & 1361.98 & 0.96 & 3136.328 & 2.212033 & 4774.622 \\ 1992 & 3003.34 & 1355.61 & 0.96 & 3127.599 & 2.216248 & 4761.333 \\ 1992 & 3007.3 & 1363.74 & 0.96 & 3131.724 & 2.205933 & 4767.612\end{array}$


Table 2a. X-Ray Fluorescence results of non-chmically treated annual rings of cross-section sample (results listed as counts per second, CPS).

\begin{tabular}{|c|c|c|c|c|c|c|c|c|c|}
\hline Year & $\begin{array}{l}\text { S } \\
\text { (CPS) }\end{array}$ & $\begin{array}{l}\mathrm{K} \\
\text { (CPS) }\end{array}$ & $\begin{array}{l}\mathrm{Ca} \\
\text { (CPS) }\end{array}$ & $\begin{array}{l}\mathrm{Ti} \\
\text { (CPS) }\end{array}$ & $\begin{array}{l}\mathrm{Ba} \\
\text { (CPS) }\end{array}$ & $\begin{array}{l}\mathrm{Mn} \\
\text { (CPS) }\end{array}$ & $\begin{array}{l}\mathrm{Fe} \\
\text { (CPS) }\end{array}$ & $\begin{array}{l}\mathrm{Zr} \\
\text { (CPS) }\end{array}$ & $\begin{array}{l}\mathrm{Pb} \\
\text { (CPS) }\end{array}$ \\
\hline 1960 & 2.894 & 99.597 & 296.808 & $\mathrm{BD}$ & 6.022 & 3.119 & 0.711 & 1.740 & $\mathrm{BD}$ \\
\hline 1961 & । & 92.943 & 286.368 & BD & 6.033 & 3.072 & 0.775 & 2.041 & $\mathrm{BD}$ \\
\hline 1962 & 2.241 & 101.131 & 287.185 & 1.392 & 7.216 & 3.144 & 0.464 & 1.985 & 0.067 \\
\hline 1963 & 2.616 & 102.67 & 275.338 & 1.451 & 5.259 & 3.08 & 0.548 & 1.659 & BD \\
\hline 1964 & 2.375 & 98.76 & 277.602 & 1.487 & 4.81 & 3.075 & 0.441 & 1.71 & $\mathrm{BD}$ \\
\hline 1965 & 2.451 & 104.542 & 267.047 & 1.087 & 5.461 & 2.92 & 0.597 & 1.894 & $\mathrm{BD}$ \\
\hline 1966 & 2.351 & 97.642 & 256.447 & 1.164 & 5.481 & 2.689 & 0.49 & 1.564 & 0.104 \\
\hline 1967 & 2.196 & 100.575 & 247.951 & 0.951 & 5.333 & 2.498 & 0.487 & 1.614 & $\mathrm{BD}$ \\
\hline 1968 & 2.234 & 100.922 & 240.128 & $\mathrm{BD}$ & 6.103 & 2.464 & 0.379 & 1.623 & 0.126 \\
\hline 1969 & 2.353 & 106.725 & 233.446 & 0.836 & 5.105 & 2.231 & 0.842 & 1.572 & 0.108 \\
\hline 1970 & 2.282 & 97.445 & 224.892 & 1.71 & 4.807 & 2.179 & 0.575 & 1.699 & 0.161 \\
\hline 1971 & 2.578 & 115.459 & 254.045 & $\mathrm{BD}$ & 5.921 & 2.511 & 0.533 & 1.905 & 0.092 \\
\hline 1972 & 2.43 & 114.069 & 249.254 & 2.076 & 5.449 & 2.425 & 0.53 & 1.672 & 0.186 \\
\hline 1973 & 2.407 & 111.611 & 241.245 & 1.901 & 5.457 & 2.463 & 0.457 & 1.644 & 0.125 \\
\hline 1974 & 2.664 & 124.091 & 236.49 & 1.329 & 5.15 & 2.426 & 0.567 & 1.742 & 0.075 \\
\hline 1975 & 2.482 & 111.377 & 231.098 & 1.393 & 5.937 & 2.347 & 0.861 & 1.51 & 0.11 \\
\hline 1976 & 2.376 & 116.285 & 231.6 & 1.275 & 5.206 & & & & \\
\hline 1976 & 2.601 & 116.057 & 231.042 & 1.183 & 5.911 & 2.399 & 0.545 & 1.727 & 0.139 \\
\hline 1977 & 2.397 & 115.453 & 224.349 & 0.755 & 6.033 & & & & \\
\hline 1977 & 2.636 & 116.215 & 223.313 & 1.114 & 5.713 & 2.286 & 0.685 & 1.708 & 0.215 \\
\hline 1978 & 2.556 & 119.501 & 214.274 & 1.878 & 4.965 & 2.326 & 1.001 & 1.724 & 0.14 \\
\hline 1979 & 2.4 & 116.614 & 205.596 & 2.367 & 3.842 & 2.19 & 0.895 & 1.365 & 0.078 \\
\hline 1979 & 2.705 & 117.171 & 206.215 & 2.084 & 4.322 & 2.162 & 0.896 & 1.611 & 0.105 \\
\hline 1979 & 2.404 & 116.366 & 206.387 & 1.16 & 4.831 & 2.213 & 1.007 & 1.65 & 0.077 \\
\hline
\end{tabular}


Table 2a. cont.

\begin{tabular}{|c|c|c|c|c|c|c|c|c|c|}
\hline Year & $\begin{array}{l}\mathrm{S} \\
(\mathrm{CPS})\end{array}$ & $\begin{array}{l}\mathrm{K} \\
\text { (CPS) }\end{array}$ & $\begin{array}{l}\mathrm{Ca} \\
\text { (CPS) }\end{array}$ & $\begin{array}{l}\mathrm{Ti} \\
\text { (CPS) }\end{array}$ & $\begin{array}{l}\mathrm{Ba} \\
\text { (CPS) }\end{array}$ & $\begin{array}{l}\mathrm{Mn} \\
\text { (CPS) }\end{array}$ & $\begin{array}{l}\mathrm{Fe} \\
(\mathrm{CPS})\end{array}$ & $\begin{array}{l}\mathrm{Zr} \\
\text { (CPS) }\end{array}$ & $\begin{array}{l}\mathrm{Pb} \\
\text { (CPS) }\end{array}$ \\
\hline 1980 & 2.425 & 117.49 & 202.665 & $\mathrm{BD}$ & 5.153 & 2.234 & 0.613 & 1.375 & 0.086 \\
\hline 1981 & 2.493 & 110.182 & 192.075 & 1.454 & 4.708 & 1.995 & 0.659 & 1.54 & 0.13 \\
\hline 1982 & 2.348 & 111.033 & 186.001 & 1.729 & 4.467 & 1.917 & 0.649 & 1.304 & $\mathrm{BD}$ \\
\hline 1983 & 2.343 & 110.06 & 182.167 & 1.426 & 5.133 & 1.816 & 0.401 & 1.495 & 0.098 \\
\hline 1983 & 2.452 & 109.429 & 182.569 & 1.883 & 4.267 & 1.847 & 0.451 & 1.464 & $\mathrm{BD}$ \\
\hline 1983 & 2.175 & 111.127 & 184.284 & 1.254 & 4.509 & 2.028 & 0.506 & 1.444 & 0.084 \\
\hline 1984 & 2.28 & 108.984 & 177.871 & 1.541 & 4.103 & 1.871 & 0.489 & 1.49 & $\mathrm{BD}$ \\
\hline 1985 & 2.34 & 107.627 & 174.181 & 0.743 & 4.795 & 1.74 & 0.575 & 1.42 & $\mathrm{BD}$ \\
\hline 1986 & 2.45 & 118.016 & 176.745 & 2.089 & 3.765 & 1.775 & 0.51 & 1.308 & $\mathrm{BD}$ \\
\hline 1986 & 2.68 & 117.544 & 177.166 & 1.888 & 4.246 & 1.851 & 0.496 & 1.455 & $\mathrm{BD}$ \\
\hline 1987 & 2.456 & 111.207 & 170.52 & 2.038 & 4.248 & 1.641 & 1.035 & 1.28 & $\mathrm{BD}$ \\
\hline 1988 & 2.373 & 109.222 & 164.6 & 1.246 & 4.339 & 1.434 & 0.474 & 1.108 & $\mathrm{BD}$ \\
\hline 1989 & 2.168 & 105.526 & 155.364 & 0.726 & 4.819 & 1.62 & 0.682 & 1.03 & $\mathrm{BD}$ \\
\hline 1990 & 2.527 & 117.661 & 155.387 & 1.843 & 3.903 & 1.818 & 0.665 & 1.371 & $\mathrm{BD}$ \\
\hline 1991 & 2.893 & 135.805 & 153.453 & 2.215 & 3.558 & 1.953 & 0.706 & 1.297 & $\mathrm{BD}$ \\
\hline 1992 & 2.723 & 135.864 & 141.965 & 2.165 & 3.178 & 1.891 & 0.625 & 1.227 & $\mathrm{BD}$ \\
\hline 1993 & 5.279 & 212.088 & 380.592 & 1.617 & 12.041 & 4.974 & 1.019 & 3.43 & $\mathrm{BD}$ \\
\hline Bark & 14.386 & 313.275 & 7118.754 & 7.637 & 47.567 & 17.129 & 1.35 & 8.179 & 0.017 \\
\hline Blank & 0.957 & 1.022 & 1.37 & 1.089 & 0.209 & $\mathrm{BD}$ & $\mathrm{BD}$ & $\mathrm{BD}$ & $\mathrm{BD}$ \\
\hline Blank & 0.869 & 0.824 & 1.394 & 1.395 & $\mathrm{BD}$ & $\mathrm{BD}$ & 0.358 & 0.041 & $\mathrm{BD}$ \\
\hline Blank & 0.966 & 1.026 & 1.239 & 1.058 & $\mathrm{BD}$ & 0.028 & 0.318 & $\mathrm{BD}$ & $\mathrm{BD}$ \\
\hline
\end{tabular}


Table $2 \mathrm{~b}$. Concentration (in ppm) of selected trace metals in tree-rings, NIST standard used to determine calibration. Missing data are not reported within 2 sigma of detection limit.

\begin{tabular}{|c|c|c|c|c|c|}
\hline Year & $\mathrm{K}$ & $\mathrm{Ca}$ & $\mathrm{Mn}$ & $\mathrm{Fe}$ & $\mathrm{Pb}$ \\
\hline 1960 & 75.39 & 136.84 & & & \\
\hline 1961 & 70.35 & 132.03 & 107.78 & 17.41 & \\
\hline 1962 & 76.55 & 132.40 & 110.31 & 10.42 & 0.30 \\
\hline 1963 & 77.71 & 126.94 & 108.06 & 12.31 & \\
\hline 1964 & 74.75 & 127.99 & 107.89 & 9.91 & \\
\hline 1965 & 79.13 & 123.12 & 102.45 & 13.41 & \\
\hline 1966 & 73.91 & 118.23 & 94.34 & 11.01 & 0.46 \\
\hline 1967 & 76.13 & 114.32 & 87.64 & 10.94 & \\
\hline 1968 & 76.39 & 110.71 & 86.45 & 8.51 & 0.56 \\
\hline 1969 & 80.78 & 107.63 & 78.27 & 18.91 & 0.48 \\
\hline 1970 & 73.76 & 103.69 & 76.45 & 12.92 & 0.72 \\
\hline 1971 & 87.39 & 117.13 & 88.10 & 11.97 & 0.41 \\
\hline 1972 & 86.34 & 114.92 & 85.08 & 11.90 & 0.83 \\
\hline 1973 & 84.48 & 111.22 & 86.41 & 10.27 & 0.56 \\
\hline 1974 & 93.93 & 109.03 & 85.12 & 12.74 & 0.33 \\
\hline 1975 & 84.30 & 106.55 & 82.34 & 19.34 & 0.49 \\
\hline 1976 & 88.02 & 106.78 & & & \\
\hline 1976 & 87.84 & 106.52 & 84.17 & 12.24 & 0.62 \\
\hline 1977 & 87.39 & 103.43 & & & \\
\hline 1977 & 87.96 & 102.96 & 80.20 & 15.39 & 0.96 \\
\hline 1978 & 90.45 & 98.79 & 81.61 & 22.48 & 0.62 \\
\hline 1979 & 88.27 & 94.79 & 76.84 & 20.10 & 0.35 \\
\hline 1979 & 88.69 & 95.07 & 75.85 & 20.13 & 0.47 \\
\hline 1979 & 88.08 & 95.15 & 77.64 & 22.62 & 0.34 \\
\hline 1980 & 88.93 & 93.44 & 78.38 & 13.77 & 0.38 \\
\hline 1981 & 83.40 & 88.56 & 69.99 & 14.80 & 0.58 \\
\hline 1982 & 84.04 & 85.75 & 67.26 & 14.58 & \\
\hline 1983 & 83.30 & 83.99 & 63.71 & 9.01 & 0.44 \\
\hline 1983 & 82.83 & 84.17 & 64.80 & 10.13 & \\
\hline 1983 & 84.11 & 84.96 & 71.15 & 11.37 & 0.37 \\
\hline 1984 & 82.49 & 82.01 & 65.64 & 10.98 & \\
\hline 1985 & 81.46 & 80.31 & 61.05 & 12.92 & \\
\hline 1986 & 89.33 & 81.49 & 62.28 & 11.46 & \\
\hline 1986 & 88.97 & 81.68 & 64.94 & 11.14 & \\
\hline 1987 & 84.17 & 78.62 & 57.57 & 23.25 & \\
\hline 1988 & 82.67 & 75.89 & 50.31 & 10.65 & \\
\hline 1989 & 79.87 & 71.63 & 56.84 & 15.32 & \\
\hline 1990 & 89.06 & 71.64 & 63.78 & 14.94 & \\
\hline 1991 & 102.79 & 70.75 & 68.52 & 15.86 & \\
\hline 1992 & 102.84 & 65.45 & 66.35 & 14.04 & \\
\hline 1993 & 160.53 & 175.47 & 174.51 & 22.89 & \\
\hline 1994 & 237.12 & 3282.06 & 600.97 & 30.32 & 0.08 \\
\hline
\end{tabular}


Table 3. Gamma-Spectrometry Counts per minute (cpm)/100gm (normalized for background cellulose countrate).

\begin{tabular}{|c|c|c|c|c|c|c|c|c|c|}
\hline Year & Wt $(\mathrm{kg})$ & ${ }^{226} \mathrm{Ra}$ & ${ }^{212} \mathrm{~Pb}$ & ${ }^{214} \mathrm{~Pb}$ & ${ }^{208} \mathrm{Tl}$ & ${ }^{214} \mathrm{Bi}$ & ${ }^{137} \mathrm{Cs}$ & ${ }^{228} \mathrm{Ac}$ & ${ }^{40} \mathrm{~K}$ \\
\hline 1960 & 0.0960 & 0.42 & 5.26 & 6.33 & 0.48 & 5.06 & 6.19 & -3.60 & 10.82 \\
\hline 961 & 0.1120 & -1.77 & 4.56 & 8.76 & -5.04 & 4.66 & 3.34 & 2.18 & 9.87 \\
\hline 962 & 0.1150 & -2.47 & 4.69 & 4.99 & -0.76 & 2.22 & 8.18 & -0.28 & 3.88 \\
\hline 963 & 0.1175 & -0.55 & 2.92 & 6.99 & 1.20 & 5.06 & 5.48 & 1.08 & 7.14 \\
\hline 964 & 0.1245 & -12.07 & 1.96 & 5.46 & 0.40 & 4.64 & 6.11 & 1.37 & 10.46 \\
\hline 965 & 0.1515 & -2.12 & -5.55 & 3.73 & -0.31 & 3.72 & 4.24 & 1.21 & 8.17 \\
\hline 966 & 0.1290 & -1.50 & 4.55 & 8.34 & 0.74 & 4.44 & 4.48 & 1.00 & 11.02 \\
\hline 967 & 0.1700 & -0.22 & 4.09 & 4.43 & 0.01 & 4.31 & 4.42 & 0.58 & 8.30 \\
\hline 968 & 0.1416 & -0.25 & 2.27 & 7.42 & -3.99 & 5.57 & 4.26 & 1.46 & 9.94 \\
\hline 969 & 0.1275 & -2.07 & 6.25 & 7.85 & 1.31 & 3.55 & 3.56 & 1.97 & 11.61 \\
\hline 970 & 0.1345 & -11.18 & 4.01 & 5.90 & -4.20 & 2.94 & 4.54 & -0.79 & 11.16 \\
\hline 971 & 0.1795 & -0.10 & 6.29 & 7.60 & 1.58 & 4.11 & 5.24 & 1.47 & 6.79 \\
\hline 972 & 0.1160 & 2.02 & 0.81 & 6.04 & -4.87 & 4.34 & 5.73 & 1.50 & 11.13 \\
\hline 973 & 0.1 & -0.65 & 3.46 & 3.71 & -0.17 & 2.55 & 3.85 & 0.02 & 2.92 \\
\hline 974 & 0.1596 & 0.03 & 7.50 & 6.92 & 1.61 & 6.72 & 3.23 & -2.16 & 1.46 \\
\hline 975 & 0.16 & -8.89 & 4.70 & 3.29 & 0.03 & 2.46 & 3.68 & 0.75 & 7.98 \\
\hline 976 & 0.1600 & -2.48 & 2.90 & 4.02 & 1.16 & 1.91 & 3.43 & 1.41 & 6.00 \\
\hline 977 & 0.1850 & -1.86 & 0.18 & 2.94 & -3.05 & 1.48 & 3.00 & -1.87 & 3.31 \\
\hline 1978 & 0.1870 & -0.53 & 5.12 & 6.24 & 0.41 & 2.21 & 3.16 & 1.32 & 5.86 \\
\hline 979 & 0.2097 & 0.92 & 2.81 & 6.26 & -0.10 & 3.50 & 3.42 & 0.71 & 4.75 \\
\hline 1980 & 0.2006 & -0.79 & 4.75 & 2.51 & 0.58 & 2.01 & 3.86 & 0.56 & 6.35 \\
\hline 981 & 0.1870 & -0.03 & 4.91 & -1.93 & 0.32 & 1.54 & 2.56 & -1.85 & 2.63 \\
\hline 982 & 0.1816 & -0.72 & 5.33 & 1.31 & -3.11 & -2.54 & 3.89 & -1.90 & 3.74 \\
\hline 1983 & 0.1 & 0.87 & 3.35 & 3.07 & -0.13 & 2.60 & 3.80 & 1.28 & 6.20 \\
\hline 1984 & 0.1775 & -2.57 & 4.17 & -2.03 & 0.83 & 1.40 & 3.57 & 0.57 & 8.71 \\
\hline 985 & 0.1790 & -0.76 & 5.06 & 3.35 & -0.06 & 2.07 & 4.06 & 1.31 & 9.19 \\
\hline 1986 & 0.1766 & -1.57 & 4.02 & 2.80 & 0.25 & 2.35 & 2.75 & 1.62 & 6.48 \\
\hline 987 & 0.1764 & 1.44 & 4.74 & 3.81 & -3.20 & 1.36 & 3.40 & 1.17 & 5.18 \\
\hline 1988 & 0.1764 & -2.18 & 6.79 & 4.09 & 1.05 & 1.60 & 3.41 & 0.66 & 6.47 \\
\hline 1989 & 0.1794 & 2.80 & 4.25 & 2.34 & 1.72 & 2.01 & 3.96 & 1.15 & 6.89 \\
\hline 1990 & 0.1778 & 1.15 & 3.04 & 3.03 & 0.40 & 2.37 & 3.54 & 0.64 & 7.87 \\
\hline 991 & 0.1771 & 0.29 & 3.44 & 2.57 & -3.19 & 3.39 & 5.00 & 1.70 & 9.06 \\
\hline 1992 & 0.1756 & -1.96 & -4.79 & 0.95 & -3.22 & 1.80 & 3.29 & 0.17 & 8.46 \\
\hline 1993 & 0.1470 & 4.65 & 8.84 & 19.62 & 0.62 & 13.29 & 7.31 & 2.85 & 14.77 \\
\hline Bark & 0.2760 & 33.91 & 37.45 & 127.1 & 13.02 & 84.26 & 12.42 & 8.66 & 9.21 \\
\hline
\end{tabular}

